\title{
Exploration of Multifunctional Properties of Piper Betel Leaves Extract Incorporated Polyvinyl Alcohol- Oxidized Maize Starch Blend Films for Active Packaging Application
}

Vishram D Hiremani

Karnatak University Dharwad

Naganagouda Goudar

Karnatak University Dharwad

Tilak Gasti

Karnatak University Dharwad

Sheela Khanapure

Karnatak University Dharwad

Vinayak $\mathbf{N}$ Vanjeri

Karnatak University Dharwad

Sarala Sataraddi

Karnatak University Dharwad

Oshin Jacintha Dsouza

Karnatak University Dharwad

Shyam Kumar Vootla

Karnatak University Dharwad

Saraswati P Masti

Karnatak Science College Dharwad

Ravindra B Malabadi

Miller,Blvd,NW,Edmonton,AB,Canada

Ravindra B Chougale ( $\sim$ chougalerkud19@gmail.com)

Karnatak University Dharwad https://orcid.org/0000-0003-3004-2044

\section{Research Article}

Keywords: Mechanical, Thermal, Biodegradable, Antibacterial, Antioxidant.

Posted Date: February 15th, 2021

DOI: https://doi.org/10.21203/rs.3.rs-177928/v1 
License: (c) (i) This work is licensed under a Creative Commons Attribution 4.0 International License. Read Full License

Version of Record: A version of this preprint was published at Journal of Polymers and the Environment on September 1st, 2021. See the published version at https://doi.org/10.1007/s10924-021-02277-1. 


\title{
Exploration of Multifunctional Properties of Piper Betel Leaves Extract Incorporated Polyvinyl alcohol-Oxidized Maize Starch Blend Films for Active Packaging Application
}

\author{
Vishram D. Hiremani ${ }^{\mathrm{a}}$ Naganagouda Goudar $^{\mathrm{a}}$, Tilak Gasti $^{\mathrm{a}}$, Sheela Khanapure ${ }^{\mathrm{b}}$ Vinayak N. \\ Vanjeri $^{\mathrm{a}}$, , Sarala Sataraddi ${ }^{\mathrm{a}}$, Oshin Jacintha Dsouza ${ }^{\mathrm{a}}$, Shyam Kumar Vootla ${ }^{\mathrm{b}}$, Saraswati P. \\ Masti $^{\mathrm{c}}$, Ravindra B. Malabadi ${ }^{\mathrm{d}}$, Ravindra B. Chougale $\mathrm{a}^{\mathrm{a}^{*}}$
}

a $P$ G Department of Studies in Chemistry, Karnatak University, Dharwad - 580 003, India

${ }^{b}$ Department of Biotechnology and Microbiology, Karnatak University, Dharwad - 580 003, India

${ }^{c}$ Department of Chemistry, Karnatak Science College, Dharwad - 580 001, India ${ }^{d}$ Miller Blvd, NW, Edmonton, AB, Canada.

$\mathrm{a}^{*}$ Corresponding Author e-mail: chougalerkud19@gmail.com

\begin{abstract}
This study explains the development of eco-friendly polyvinyl alcohol (PVA)/oxidized maize starch (OMS)/Betel leaves extract (BLE) blend films by employing a cost effective technique. The influence of BLE on structural, Thermal, Mechanical, Morphological, Optical, Antibacterial, and Antioxidant properties of PVA/OMS blend were investigated successfully by applying FTIR, TGA, DSC, UTM, SEM, UV spectroscopy, In vitro antibacterial and DPPH scavenging activity. The hydrogen bonding interaction among the components of the blend films led to enhance thermal stability, miscibility, mechanical properties, smooth surface morphology and UV blocking properties of the blend films. The addition of BLE enormously improved the antibacterial and antioxidant properties of PVA/OMS blend films. Moreover, the water contact angle, solubility, biodegradability, Water vapour transmission rate, oxygen permeability properties of blend films were analyzed, which illustrates that the obtained films were hydrophilic, water soluble and biodegradable in nature. With regard to barrier properties the WVTR and oxygen permeability of the blend films were enhanced after doping of BLE. These experimental outcomes suggest that the BLE containing PVA/OMS films can be used for the expansion of active packaging material.
\end{abstract}

Keywords: Mechanical, Thermal, Biodegradable, Antibacterial, Antioxidant. 


\section{Introduction}

The growing trend towards the use of petroleum based plastics has generated complications in disposal when they become waste. However, these packaging materials can take hundreds of years to degrade, causing genuine ecological pollution. Worldwide researchers have committed to developing biodegradable polymers instead of synthetic polymers. [1]. Currently, special attention is paid to designing environmentally safe and cost effective polymer, such packaging materials can be achieved based on starch and polyvinyl alcohol blends [2].

Maize or Zea Mays, generally known as corn, provides a standard starch consists of two major components amylose and amylopectin. Amylose is typically a linear polysaccharide with $\alpha(1-4)$-linked D glucose units build up to $15-35 \%$ of granules in most of the plants, amylopectin which is a major constituent of starch, consists of anhydroglucose units with a particularly branched structure represents about $5 \%$ of $\alpha$-(1-6)-linked branches, which have a profound effect on the physical and biological properties [3-5].

However native starch dose not exhibit appropriate properties required for potential applications, due to their susceptibility to extreme $\mathrm{pH}$, low thermal stability and strong retrogradation properties [6]. Chemical modification of amylose and amylopectin via chemical, physical or enzymatic method is a classical way to effectively improve the properties of parent starch and also useful for various industrial applications [7]. Among the chemical modification oxidation of native starch in presence of the oxidizing agent is one of the modification method, in which hydroxyl group of starch molecule oxidized to carboxyl and carbonyl functional groups, by means of subsequent depolymerisation of the starch [8-9]. oxidized starch shows low viscosity, high solubility, high stability, good transparency and excellent film forming and binding properties [10-11]. Oxidized starch is widely used to develop packaging material in the food industries, especially as an edible film. Nevertheless, it is used in applications where film formation and adhesion properties are desired [12].

Polyvinyl alcohol (PVA) is artificial, non toxic, water soluble polymer having a wide range of properties like flexibility, strong conglutination, good physical, chemical properties and also has a good film foaming capacity [13-14]. PVA is used for many applications like drug delivery, packaging, and it is comparatively used for low cost productions [15]. Due to the presence of $\mathrm{OH}$ groups, PVA has more capacity for formation of hydrogen bonding therefore it is widely utilized for the development of blend films with natural polymers.

To progress the properties of binary blend films inclusion of additives into the blend matrix is one of the extensively used technique. Incorporation of active components like, 
fatty acids, organic acids, and plant extracts into blend matrix improves the functionality of the films and has been used as an alternative to the conventional packaging [16]. The phenolic compounds of plant extract have received more interest as they exhibit strong antioxidant as well as antimicrobial properties [17]. The addition of plant extract into polymer matrix modifies the physicochemical and biological activities of packaging materials and also enhances the shelf life and durability of the film, hence it is potential for food packaging applications. The green heart shaped betel leaves are popularly known as paan in India. The piper betle $L$. is the scientific name of the betel, belongs to the family of black pepper known as Piperaceae [18]. These betel leaves contain large amount of antioxidants like eugenol, ascorbic acid, hydroxychavicol, $\beta$-carotene and the extract of these leaves are attributed to its antimicrobial [19], antifungal, and anti-inflammatory [20], as well as radioprotective, immunomodulatory properties have been reported earlier [21-23]. In addition to these properties, the fresh juice of betel leaves is used for ayurvedic and pharmacological applications [24]. Therefore based on the literature survey, we have chosen the betel leaves extract as active component in this study to prepare biodegradable packaging material.

The main goal of this research was to develop, ethanolic leaves extract of piper betel incorporated Polyvinyl alcohol/Oxidized Maize Starch blend films for active packaging application. To the best of our knowledge, reports on PVA/OMS/BLE have been not published so far. Meanwhile, the present study aims to evaluate the influence of betel leaves extract on the physicochemical and biological properties of PVA /OMS blend matrix.

\section{Experimental}

\section{Materials}

Oxidized maize starch (OMS) with approximately $11 \%$ moisture was provided by Millennium Starch India Pvt.Ltd., Athani, Karnataka, India. Polyvinyl alcohol (Degree of polymerization $1700 \pm 50$, 99\% Hydrolysed, Molecular weight 1, 15,000) was supplied by Loba Chime Pvt.Ltd. Mumbai, Maharashtra, India. Fresh Pipper Betel leaves free from physical damage were purchased from the local market, Dharwad, Karnataka, India. Ethanol is procured from Loba Chime Pvt.Ltd. Mumbai, Maharashtra. Double distilled water is used throughout the experiments.

\section{Preparation of Betel leaves extract (BLE)}

The betel leaves extract was prepared by previously described method [25] with some modification. Betel leaves were washed with tap water and then with double distilled water moreover dried in shade at room temperature. After the drying leaves were crushed with the 
help of mortar and pestle. $10 \mathrm{~g}$ of powdered sample were dissolved in $90 \%$ ethanol for $4 \mathrm{hrs}$ and then extracted by continuously stirring overnight at room temperature using a magnetic stirrer (REMI Model 1-ML, Remi Electrotechnik Ltd, Vasai, India). The extract was filtered using Whatman No 1 filter paper and the residue remained on filter paper was transferred into the same beaker and re-extracted until the residue becomes colourless. The plant extract was stored in refrigerator at $4^{\circ} \mathrm{C}$ in an amber coloured bottle to avoid direct exposure to light, until further analysis.

\section{Fabrication of Blend Films}

The betel leaf extracts (BLE) incorporated PVA/OMS blend films were fabricated by employing a user friendly solvent casting technique. PVA solution was prepared by dissolving $1.8 \mathrm{~g}$ of PVA into a definite volume of double distilled water followed by heating at $90^{\circ} \mathrm{C}$ on a magnetic stirrer at $200 \mathrm{rpm}$. Oxidized maize starch of $0.2 \mathrm{~g}$ was dissolved in a definite quantity of double distilled water and stirred at $95{ }^{\circ} \mathrm{C}$ to obtain a clear solution. Both PVA and OMS solutions were mixed and stirred for 4-5 hrs to get a clear and homogeneous solution. The different amounts of betel leaves extract $(2 \mathrm{~mL}, 4 \mathrm{~mL}, 6 \mathrm{~mL}, 8 \mathrm{~mL})$ were incorporated into the PVA/OMS blend matrix and stirred overnight at room temperature to get clear and viscous blend solution. The suspension was poured onto clean and dry petri dishes $(200 \times 20 \mathrm{~mm})$ then dried in an oven at $30{ }^{\circ} \mathrm{C}$. After evaporation of the solvent, the films were peeled off and stored in a desiccator until further characterisation.

Table 1: Quantities of PVA, OMS and BLE used for film preparation.

\begin{tabular}{cccc}
\hline Samples & PVA $(\mathrm{g})$ & OMS $(\mathrm{g})$ & BLE $(\mathrm{mL})$ \\
\hline PS & 1.8 & 0.2 & - \\
PSB-1 & 1.8 & 0.2 & 2 \\
PSB-2 & 1.8 & 0.2 & 4 \\
PSB-3 & 1.8 & 0.2 & 6 \\
PSB-4 & 1.8 & 0.2 & 8 \\
\hline
\end{tabular}

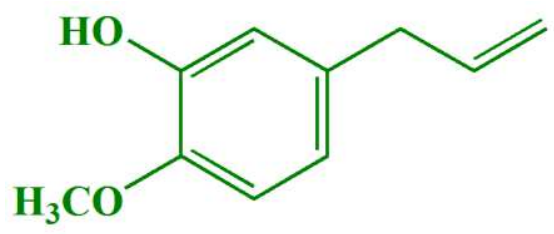

Chavibetol<smiles>C=CCc1ccc(O)c(O)c1</smiles>

Hydroxychavicol<smiles>C=CCc1ccc(O)c(OC)c1</smiles>

Eugenol

Figure 1: Representation of chemical components of betel leaf. 


\section{Measurements}

\section{Thickness Measurement}

The handheld micrometer (Mitutoyo high accuracy S700 series, Tokyo, Japan) with 0.0001 $\mathrm{mm}$ resolution was used to measure the thickness of the film. The average value was calculated by performing five replicates for each film sample. These thickness values are used to investigate the optical, water vapour transmission rate and mechanical properties.

\section{Water Solubility}

The water solubility of the prepared blend films were performed according to ASTM standard D570-98. The film samples in size $2 \times 2 \mathrm{~cm}^{2}$ were pre-dried in a hot air oven at 60 ${ }^{\circ} \mathrm{C}$ for $24 \mathrm{hrs}$. The samples were placed in a desiccator and cooled down to room temperature and then weighed as initial dry weight $\left(\mathrm{W}_{\mathrm{o}}\right)$. Further, these samples were immersed in a beaker containing $100 \mathrm{ml}$ deionised water for $24 \mathrm{hrs}$ and then films were taken out and excess water on the film were removed using blotting paper and then placed in hot air oven to get final dry weight $\left(\mathrm{W}_{\mathrm{d}}\right)$. The water solubility was calculated by using the following equation,

$$
\text { Solubility }(\%)=\frac{\mathrm{W}_{o}-\mathrm{W}_{\mathrm{d}}}{\mathrm{W}_{0}} \times 100
$$

\section{Fourier Transformed Infrared (FTIR) Spectroscopy}

The FTIR analysis of film samples were performed in order to identify the absorption bands associated with the vibrations of functional groups present in components of the blend films. The attenuated total reflection (ATR) (Perkin-Elmer Spectrum Version 10.5.4) is equipped to record the FTIR spectra. Measurements were recorded between $400-4000 \mathrm{~cm}^{-1}$ spectral ranges with resolution $4 \mathrm{~cm}^{-1}$.

\section{Mechanical Properties}

The mechanical properties of fabricated blend films were determined by using Dak System Universal Testing Machine (Series 7200-1 KN). Tensile strength ( $\mathrm{T}_{\mathrm{s}}$ ), Young's modulus $\left(\mathrm{Y}_{\mathrm{m}}\right)$, and elongation at break $\left(\mathrm{E}_{\mathrm{b}}\right)$ were measured according to ASTM-D882 standard test (ASTM, 1992). The film specimens of $(2.5 \times 10) \mathrm{cm}$ in size were placed in extension grips of the universal testing machine and the samples were stretched by fixing crosshead speed of $1 \mathrm{~mm} / \mathrm{min}$ at room temperature. Three specimens were tested for each film sample and the average value was recorded.

\section{Optical Properties}

The UV spectrum of each sample was recorded in the range of 200 to $800 \mathrm{~nm}$, by placing a specimen of size $3 \mathrm{~cm} \times 1 \mathrm{~cm}$ in a quartz cuvette of UV-Vis spectrophotometer (Model V-670). All the measurement was carried out in triplicates using a empty cell as a reference. The 
results obtained have been expressed in transmission (\%). The transparency at $600 \mathrm{~nm}\left(\mathrm{~T}_{600}\right)$ and the opacity was calculated using the below equation [26].

$$
\mathrm{T}_{600}=\frac{-\log \% \mathrm{~T}}{\mathrm{~b}}
$$

Where $\% \mathrm{~T}$ is percentage transmittance and $\mathrm{b}$ is the film thickness $(\mathrm{mm})$.

$$
\text { Opacity }=\text { Absorbance at } 500 \mathrm{~nm} \times \text { film thickness }(\mathrm{mm})
$$

\section{Scanning Electron Microscopy (SEM)}

Film specimens of size $2 \times 2 \mathrm{~mm}^{2}$ were cut from PS and PSC blended films and placed on a metal stub using a dual side gum carbon tape. Then all film specimens were laminate with a conductive layer of noble metal (10 nm thickness) to avoid charging to the high electron beam. Surface morphology and internal structure of all specimens were examined using a JEOL JSM-6360 scanning electron microscopy (SEM) at an acceleration voltage of $10 \mathrm{kV}$. SEM micrographs were taken at different magnifications.

\section{Water Vapour Transmission Rate (WVTR)}

To determine WVTR, the glass bottle having an inside diameter of $17 \mathrm{~mm}$ was taken and 10 $\mathrm{ml}$ of deionised water is poured into it and the mouth of the bottle is capped with prepared films and tightened using Teflon tape. Then the initial weight $\left(\mathrm{W}_{1}\right)$ of the bottle was recorded and kept in an oven at $40^{\circ} \mathrm{C}$ for three days. Weight changes of the bottles were recorded after every $24 \mathrm{hrs}\left(\mathrm{W}_{2}\right)$. The water vapour transmission rate was calculated using the following formula [27],

$$
\text { WVTR }=\frac{\mathrm{W}_{1}-\mathrm{W}_{2}}{\mathrm{~T} \times \mathrm{A}} \mathrm{g} / \mathrm{m}^{2} \mathrm{~h}
$$

Where, $\mathrm{W}_{1}=$ Initial weight of film sample, $\mathrm{W}_{2}=$ Final weight of film sample $\mathrm{T}=$ Time in hours, $\mathrm{A}=$ area of bottle mouth $\left(\mathrm{m}^{2}\right)$.

\section{Oxygen permeability (OP)}

The oxygen permeability of prepared films was measured according to the method reported by Yadav et al. [28]. The films were cut into $2 \times 2 \mathrm{~cm}^{2}$ in size and the mouth of the bottles $(10 \times 50 \mathrm{~mm})$ was covered with the film and sealed with a strip. Consequently, the bottles were placed in the desiccator at room temperature. The weight of every bottle were monitored every $1 \mathrm{~d}$ over $3 \mathrm{~d}$. The slope was determined by the linear regression (R2>0.99) of weight change vs. time. The OP (Oxygen Permeability) and OPTR (Oxygen Permeability Transmission Rate) were expressed by using the equation given below.

$$
\text { OPTR }=\frac{\text { Slope }}{\text { Film area }}
$$




$$
\mathrm{OP}=\frac{\mathrm{OPTR} \times \mathrm{L}}{\Delta \mathrm{P}}
$$

$\Delta \mathrm{P}=$ Difference in partial vapour pressure between the pure water and dry atmosphere $\left(0.02308 \mathrm{~atm}\right.$ at $\left.25^{\circ} \mathrm{C}\right), L$ represents the average film thickness. Measurements were determined in triplicate for each sample.

\section{Water Contact Angle (WCA)}

Water contact angle analysis was performed to acquire information on the variation of hydrophilicity of the film surfaces. A contact angle meter Model DMs-401 (Kyowa Interface Science Co. Ltd., Tokyo) was used to determine the contact angle. For this purpose, the film specimen in $3 \mathrm{~cm} \times 3 \mathrm{~cm}$ was placed on a flat glass slide and a drop of millipore water was carefully dropped onto the film surface. Then, the contact angles between the water droplet and the film surface were measured. The reported contact angle is the average value of three measurements from three different locations for each film specimen.

\section{Thermogravimetric Analysis (TGA)}

Thermal stability of the prepared blend films was determined using equipment SDT Q600 V20.9 Build 20 - Universal V4.5A TA Instruments. The film samples of 5-6 mg were taken for analysis and heated from $25^{\circ} \mathrm{C}$ to $600^{\circ} \mathrm{C}$ at a heating rate of $10^{\circ} \mathrm{C} \min ^{-1} \mathrm{~N}_{2}$ atmosphere. The weight losses at different temperature ranges were recorded.

\section{Differential scanning calorimetry (DSC)}

By using DSC Q 20 V 24.10 build 122 TA instrument, glass transition temperature ( $\mathrm{T}_{\mathrm{g}}$ ) and melting temperature $\left(\mathrm{T}_{\mathrm{m}}\right)$ of films were determined. Previously calibration of temperature and heat flux was done by using indium and zinc. Samples about 2-4 mg of each system immersed in hermetically sealed aluminum pans and heated at scanning rate $10^{\circ} \mathrm{C} / \mathrm{min}$ under a nitrogen atmosphere from room temperature to $400^{\circ} \mathrm{C}$.

\section{Biodegradation Analysis}

The biodegradation test of prepared films was investigated according to the method reported by Kaya M et al. [29]. For this film sample of size $2 \times 2 \mathrm{~cm}^{2}$ was taken and buried under soil at a depth of $5 \mathrm{~cm}$ from the surface. The soil was kept moist by sprinkling water at every 3 days for 4 weeks. The weight loss of sample was determined by removing the sample and carefully washed with distilled water and dried at $45^{\circ} \mathrm{C}$. The degradation of the specimens was calculated according to the equation given below.

$$
\text { Degradation (\%) }=\frac{M_{1}-M_{2}}{M_{1}} \times 100
$$


Where, $M_{1}$ is the initial dry weight of the sample and $M_{2}$ dry weight of the sample after the biodegradation test in soil.

\section{Antibacterial properties}

The antimicrobial activity was evaluated by the agar well diffusion method (X). The gram positive bacteria Staphylococcus aureus (NCTC 10788), gram negative bacteria Escherichia coli (ATCC 25922) were used as the test microorganisms. $100 \mu$ of the test organisms were swab inoculated onto the sterile nutrient agar plates. The wells were bored into the agar plates using a sterile cork borer ( $6 \mathrm{~mm}$ diameter). $100 \mu \mathrm{L}$ of the film solutions were added into the corresponding wells. The plates were incubated at $37^{\circ} \mathrm{C}$ for 24 hours for bacteria followed by observing and measuring the antimicrobial activity by measuring the zones of inhibition in millimeters.

\section{DPPH Scavenging Activity}

Antioxidant activities of the prepared blend films were examined by radical scavenging activity using the 2, 2-diphenyl-1-picrylhydrazyl (DPPH) method. The stock solution was prepared by dissolving $3.9432 \mathrm{mg}$ of DPPH in $100 \mathrm{ml}$ of methanol and kept at $4{ }^{\circ} \mathrm{C}$ until further use. DPPH solution of $2 \mathrm{ml}$ was mixed with $1 \mathrm{ml}$ of five various concentrations (20, 40, 60, 80 and $100 \mathrm{mg} \mathrm{mL}^{-1}$ ) of the samples. Ascorbic acid was used as a standard reference. The reaction mixture was mixed and kept in the dark for 30 min to prevent photochemical reaction and incubated at room temperature. The absorbance of reaction mixture (sample absorbance) was recorded spectrophotometrically at $517 \mathrm{~nm}$. An antioxidant activity was calculated by the following equation

$$
\text { DPPH Scavenging activity }=\frac{\mathrm{A}_{0}-\mathrm{A}_{1}}{\mathrm{~A}_{0}} \times 100
$$

Where $A_{0}$ is the absorbance of the standard solution (ascorbic acid), and $A_{1}$ is the absorbance of the prepared films.

\section{Result and discussion}

\section{Thickness and appearance of the films}

The blend films prepared from PVA/OMS/BLE (PSB) were found to be homogeneous containing smooth surface areas and easily peeled from petri dishes. Due to strong intra and inter-molecular hydrogen bonding between PVA, OMS and BLE, blend films were miscible over the entire composition. To evaluate physical properties, thickness of the film is an important parameter. All the prepared films were presented thickness values in the range of 0.05-0.07 $\mathrm{mm}$ and values are summarised in Table 3. The appearance of all the BLE 
incorporated blend films had a slight green colour. Similar outcomes were found in green tea extract doped chitosan films reported by Ubonrat et al. [30].

\section{Fourier Transform Infrared spectroscopy}

The FTIR spectra of PVA/OMS (PS) blend films, before and after the addition of Betel leaves Extract (BLE) were recorded to identify structural changes in the PS blend film.

Figure 2a shows the FTIR spectra of prepared films and corresponding peak assignment were tabulated in Table 2. The spectra of pristine PVA, pure OMS and their characteristics peaks were systematically discussed in our earlier publication [27].
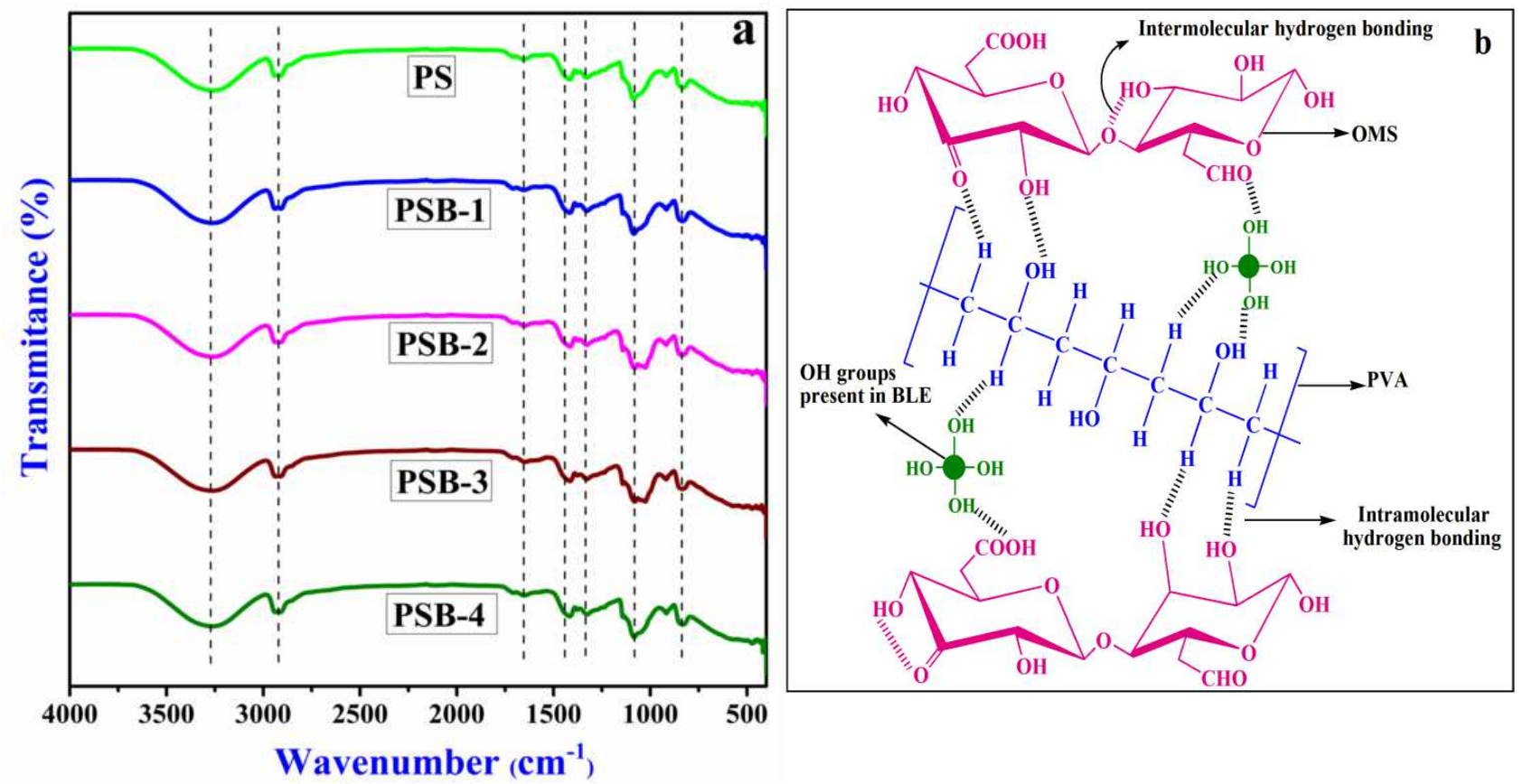

Figure 2: a) FTIR spectra of prepared blend films, b) Hydrogen bonding interaction between PVA, OMS and BLE.

After blending of PVA and OMS, the PS blend film showed an absorption peaks at $3262 \mathrm{~cm}^{-1}$ and $1654 \mathrm{~cm}^{-1}$ corresponds to stretching and bending vibration of hydroxyl groups of PVA and OMS. The peaks located at $1718 \mathrm{~cm}^{-1}, 1152 \mathrm{~cm}^{-1}$, and $1007 \mathrm{~cm}^{-1}$ are attributed to $\mathrm{C}=\mathrm{O}$ stretching, $\mathrm{C}-\mathrm{O}$ stretching in $\mathrm{C}-\mathrm{O}-\mathrm{H}$ and $\mathrm{C}-\mathrm{O}$ stretching in $\mathrm{C}-\mathrm{O}-\mathrm{C}$ respectively[31].

The successful interaction between components of PSB blend films was confirmed by the alteration of absorption peaks. In the spectrum of PSB blend films, the broad peaks located in the range of $3251-3258 \mathrm{~cm}^{-1}$ is corresponds to stretching vibration of $\mathrm{OH}$ groups, which are decreased $8 \mathrm{~cm}^{-1}$ as compared to controlled PS blend film. The $\mathrm{OH}$ bending peak located at $1654 \mathrm{~cm}^{-1}$ in PS blend also decrease to lower frequency, the peak at $2939 \mathrm{~cm}^{-1}$ in the spectrum of PS blend film shifted to lower values. These spectral results indicate the 
existence of hydrogen bonding interaction and improvement of compatibility among the components of the blend films [32].

Table 2: Peak assignment of prepared blend films.

\begin{tabular}{l|c|c|c|c|c}
\hline \multicolumn{5}{c}{ Wavenumber $\left(\mathbf{c m}^{-1}\right)$} \\
\hline & & PSB-1 & PSB-2 & PSB-3 & PSB-4 \\
\hline -OH stretching & 3262 & 3256 & 3254 & 3258 & 3251 \\
\hline C-H stretching & 2939 & 2930 & 2937 & 2936 & 2938 \\
\hline C=O stretching & 1718 & 1713 & 1716 & 1710 & 1710 \\
\hline -OH bending & 1654 & 1650 & 1654 & 1651 & 1654 \\
\hline CH bend of CH2 & 1418 & 1417 & 1414 & 1414 & 1417 \\
\hline C-O stretching in C-O-H & 1152 & 1154 & 1142 & 1138 & 1154 \\
\hline C-O stretching in C-O-C & 1007 & 1016 & 1016 & 1025 & 1030 \\
\hline CH rocking & 916 & 916 & 917 & 917 & 916 \\
\hline CH2 stretching & 831 & 834 & 833 & 831 & 833 \\
\hline
\end{tabular}

\section{Mechanical Properties}

The polymer films may be exposed to various types of stress during its use, the examination of mechanical properties involves the scientific as well as practical and technological aspects. The response of mechanical properties of control PS blend film and PS blend incorporated with betel leaves extract were shown in Figure 3 and the values of tensile strength (TS), young's modulus (YB), and elongation at break (EB) are summarised in Table 3. The control PS blend exposed well TS and EB values at $54.89 \mathrm{MPa}$ and $71.28 \%$ attributed to both PVA and OMS are polar and involve hydroxyl groups in their structure which tend to form intra and intermolecular hydrogen bonding and also promote the structural integrity of PS blend film [33]. The mechanical properties of the BLE reinforced films increased slightly at lower content of BLE and then decreased. However, the elongation at break of all the blend films containing BLE is improved as compared to the control PS blend film. Both the PVA and OMS involve compact molecular packing in the PS blend film which results in lower the \% $\mathrm{EB}$ but incorporated BLE in the PS matrix reduces the interchain attraction between PVA and OMS as a result \% EB of the films increased [34]. The young's modulus of all the PSB blend films decreased when compared to the control PS blend film. The decrease in TS, YM and the increase in \% EB proves the BLE has a plasticizing effect for PVA/OMS. The results obtained from mechanical studies are in good agreement with other researchers [35]. 

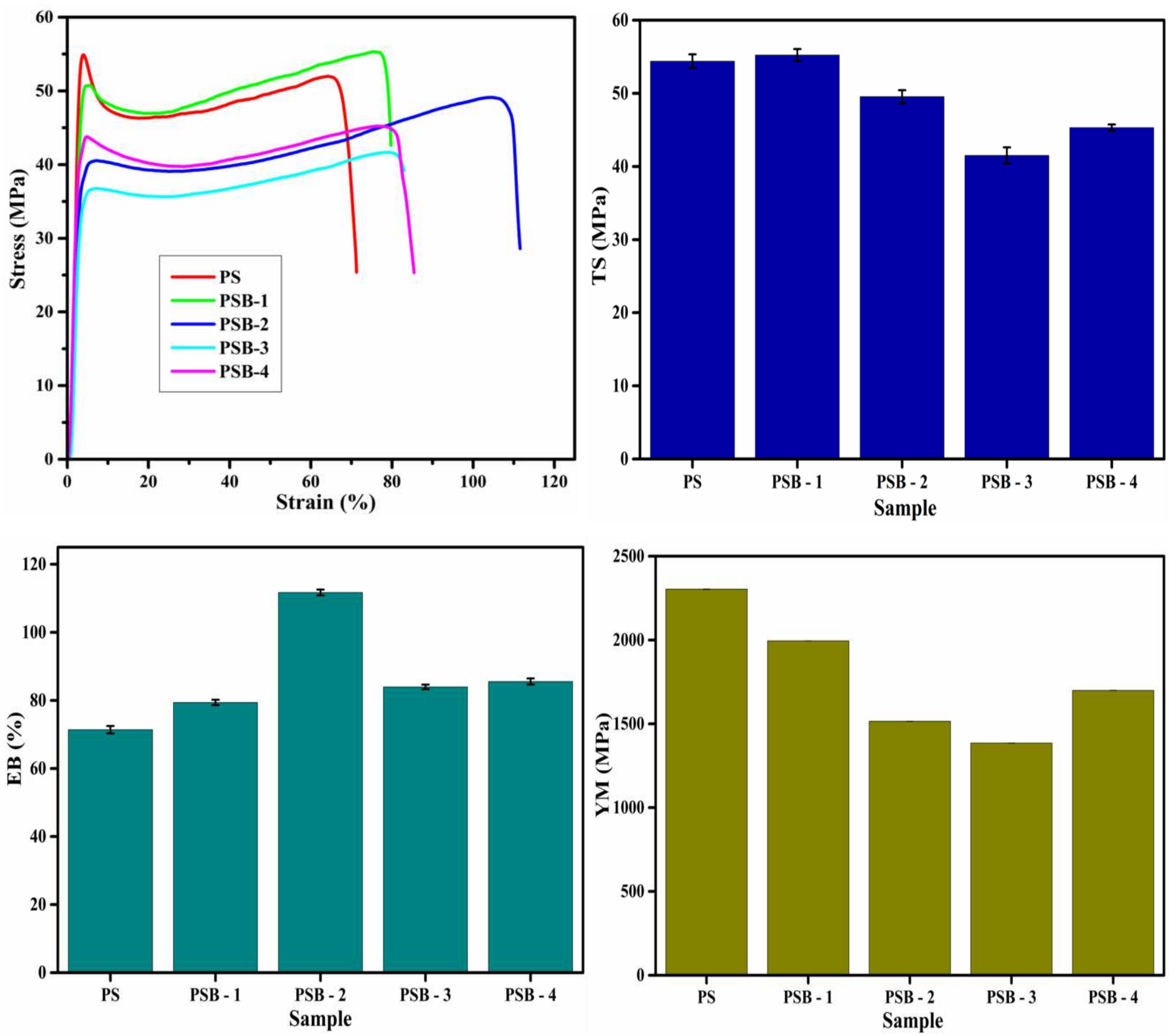

Figure 3: Mechanical properties of prepared blend films

Table 3: Mechanical properties of PS, and PSB blend films.

\begin{tabular}{ccccc}
\hline Sample & Thickness $(\mathrm{mm})$ & TS $(\mathrm{MPa})$ & EB $(\%)$ & YM (MPa) \\
\hline PS & $0.05 \pm 0.01$ & $54.89 \pm 0.93$ & $71.28 \pm 1.10$ & $2303.33 \pm 1.07$ \\
PSB - 1 & $0.06 \pm 0.01$ & $55.31 \pm 0.82$ & $79.74 \pm 0.79$ & $1995.02 \pm 0.65$ \\
PSB -2 & $0.07 \pm 0.02$ & $49.11 \pm 0.90$ & $111.61 \pm 0.85$ & $1515.42 \pm 1.14$ \\
PSB -3 & $0.07 \pm 0.02$ & $41.67 \pm 1.10$ & $83.05 \pm 0.67$ & $1385.05 \pm 1.15$ \\
PSB -4 & $0.06 \pm 0.01$ & $45.20 \pm 0.43$ & $85.44 \pm 0.88$ & $1699.80 \pm 1.01$ \\
\hline
\end{tabular}




\section{Water Solubility}

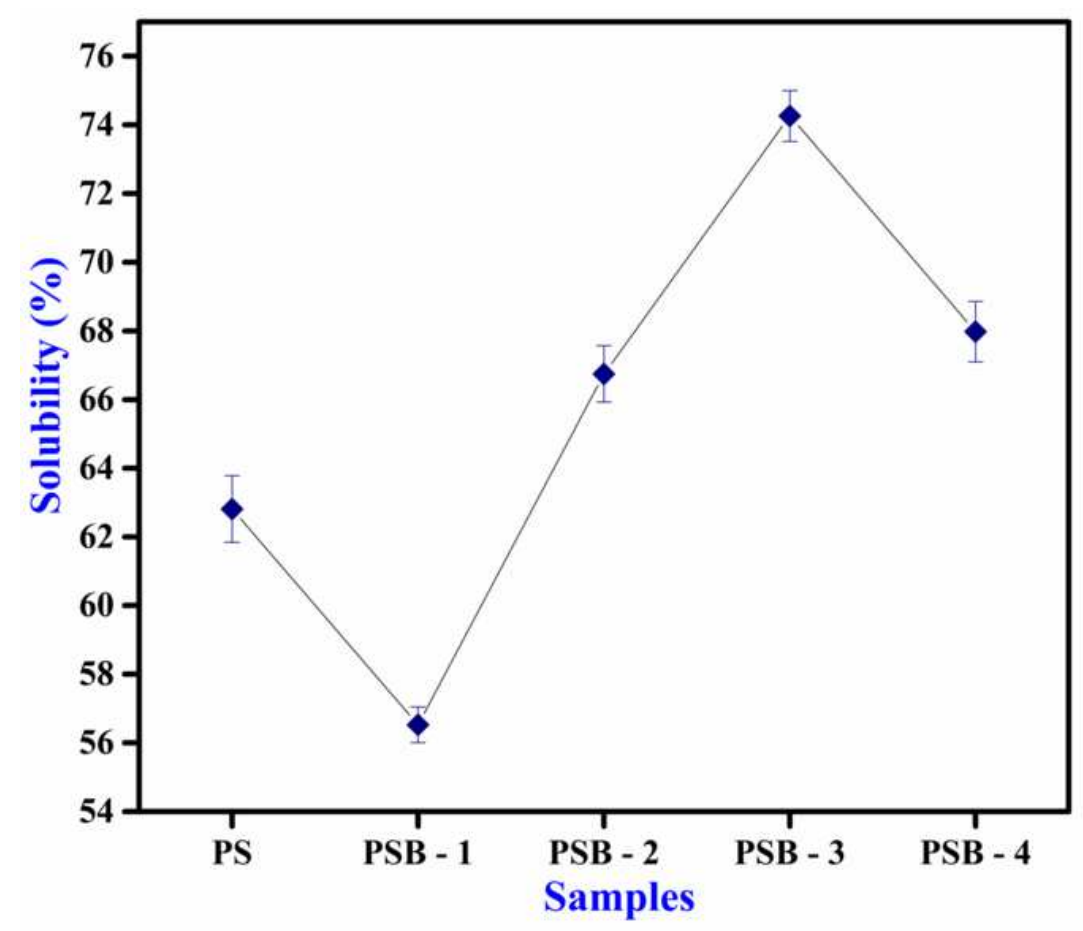

Figure 4) Solubility percentage of prepared blend films.

Water solubility is an important parameter that determines the biodegradability of the film when used as a packaging material [36]. Higher or complete solubility of films can be helpful in degradation, while lower solubility of films applicable for storage [37]. Figure 4 shows the solubility percentage of all the prepared films. The solubility of PSB-1 blend film decreased as compared to control PS blend film, this might be due to the occurrence of polymer interaction restricted the mobility of polymer chain, thus decreased the hydrophilicity of the film leading to reduce the water affinity [38]. Nevertheless, the blend films except PSB-1, exhibited higher solubility in contrast with control PS blend. These observations are consistent with results obtained from mechanical properties. BLE contains the phenolic compounds which involve the hydroxyl groups in their structure therefore incorporation of BLE in the PS matrix increased the hydroxyl group in the blend can be cause to increase the solubility. Maizura et al. also reported similar results for another plant extract [39].

\section{Optical properties}

Optical properties are one of the most important characteristics of packaging films that should prevent food from UV radiation. These UV radiations are creates various deteriorative effects that reduce the nutritional quality of food [40]. Figure 5(a) shows the percentage light transmittance of the prepared films. From the figure, it can be depicted that blend films containing BLE presented low light transmission percentage as compared to PS blend film in 
the UV region, especially at 200-350nm wavelength. Increasing the quantity of the BLE in the PS blends also improved the light barrier properties attributed to the existence of aromatic hydroxyl groups in the BLE increased the absorbance in the UV region. The obtained results are in good agreement with Gomez-Guillen et al. who prepare the gelatin based films containing murta leaves extract improved light barrier properties with the incorporation of leaves extract [41]. Figure 5b and 5c represents the transparency and opacity of the prepared blend films. The inclusion of BLE in the PS matrix exhibited higher opacity and subsequently lower transparency as compare to PS blend films. This might be due to the addition of BLE in the PS matrix reduced the polymer interchain spacing caused to increase the opacity by permitting less light to pass through the film [42]
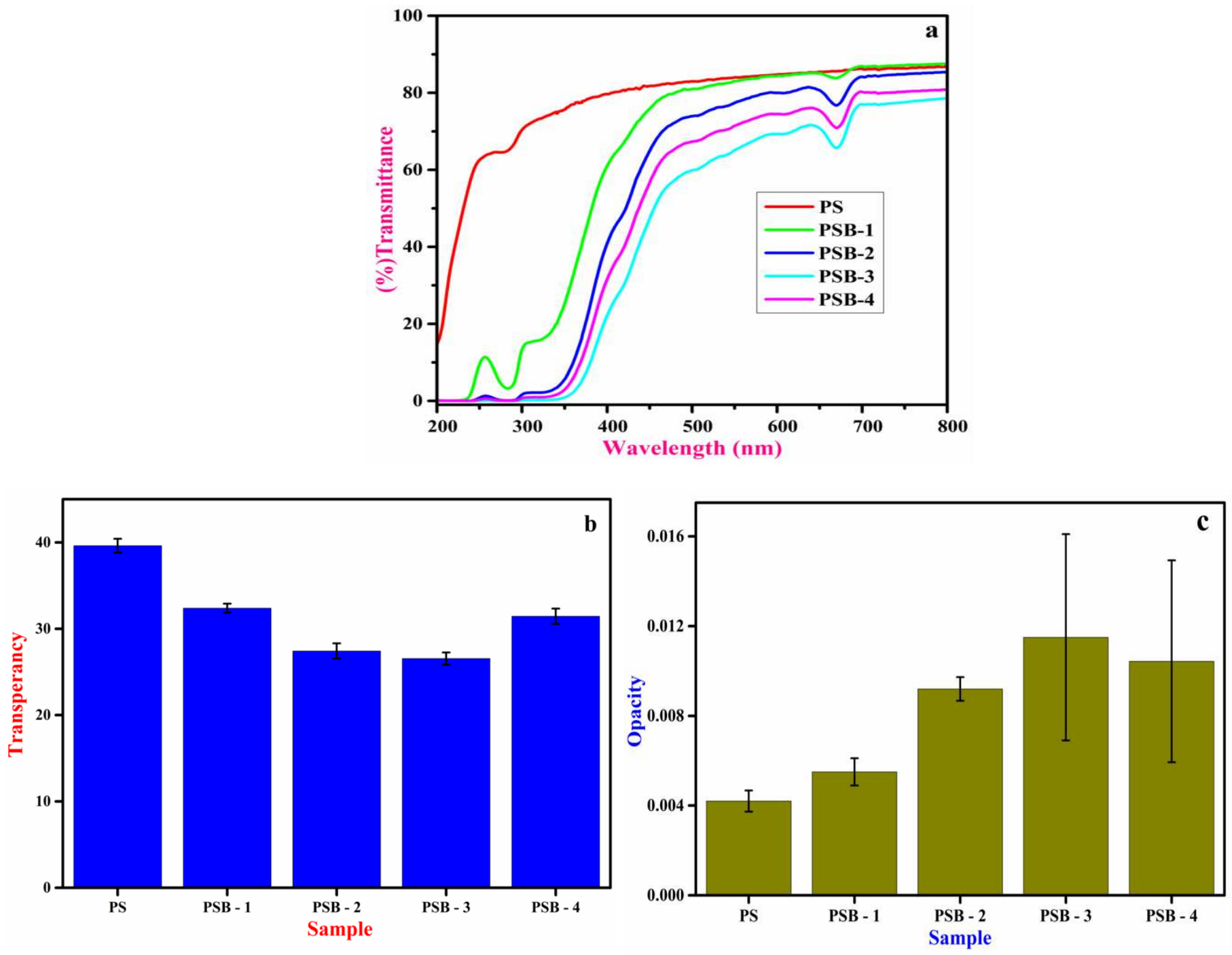

Figure 5: a) \% Transmittance, b) transparency and c) opacity of the prepared blend films 


\section{Water Contact Angle Measurement}

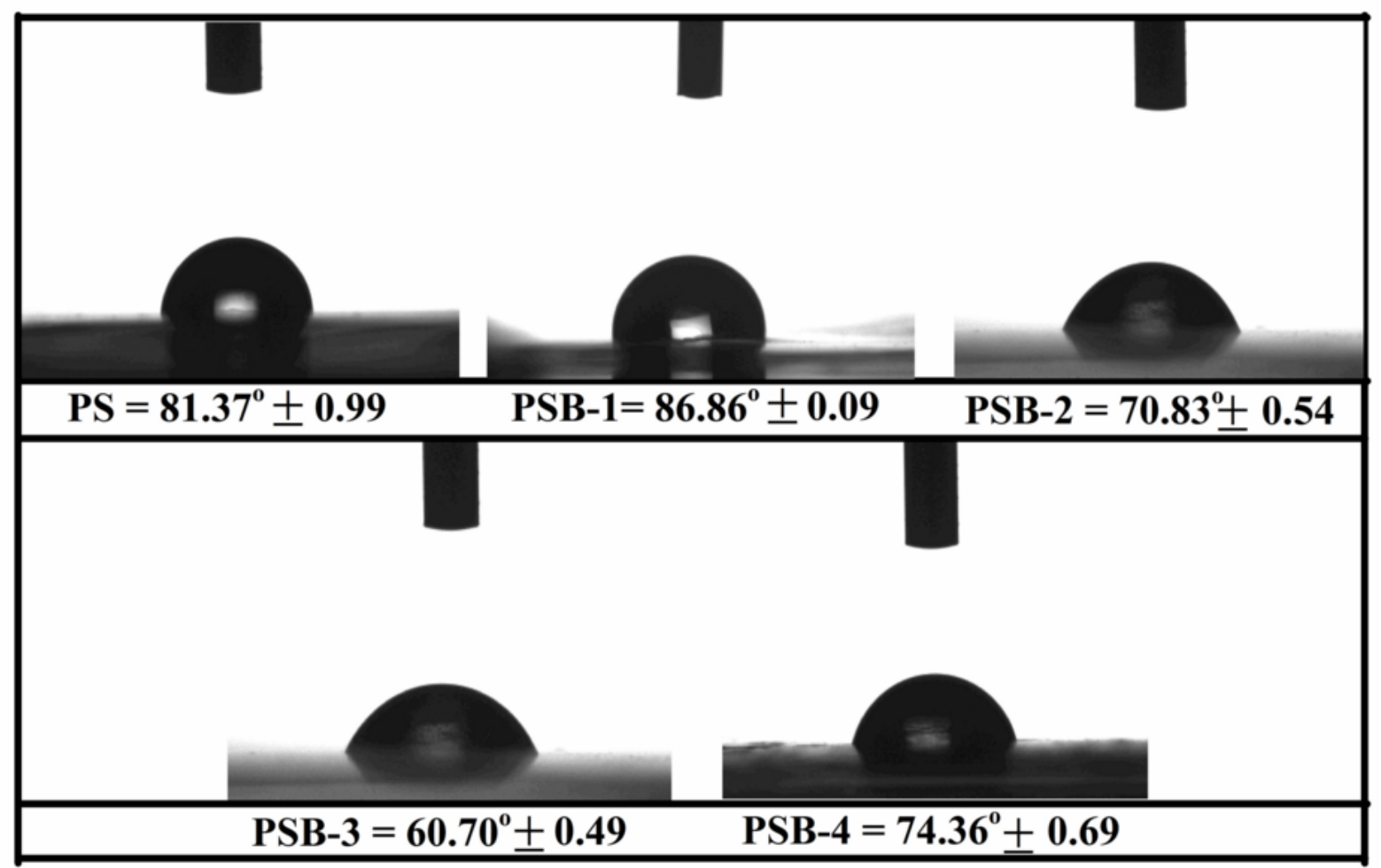

Figure 6: Water contact angle images of prepared films.

Water contact angle measurement was carried out to evaluate the ability of water drop to maintain contact with a film surface. In other words, the contact angle can indicate the hydrophilic or hydrophobic nature of the film. Generally, it is known that a contact angle lower than $90^{\circ}$ referred as a hydrophilic surface (high wettability) whilst a contact angle higher than $90^{\circ}$ indicates the hydrophobic surface (low wettability) [43]. The water contact angle of the obtained films was exposed in Figure 6. The contact angle of control PS blend was found $81.37^{\circ}$. A similar trend was observed in the oxidized starch and gelatine composite films reported by Yajuan Wang et al [44]. From the data, it can be concluded that the incorporation of the BLE into the PS mixture increases the value of contact angle initially and then decreased. The enhancement in the contact angle at the lower dopant level of BLE (PSB1) attributes to the interaction between components of the blend films ties the hydroxyl groups of both PVA and OMS. The reduction found in the contact angles of PSB-2, PSB-3, and PSB-4 blend films as compare to control PS blend film which might be due to an increase in the polar groups in the blend films at higher content of BLE [33]. Results obtained from the contact angle are in good relevance with previously discussed solubility studies. 


\section{Water vapour transmission rate and Oxygen Permeability}
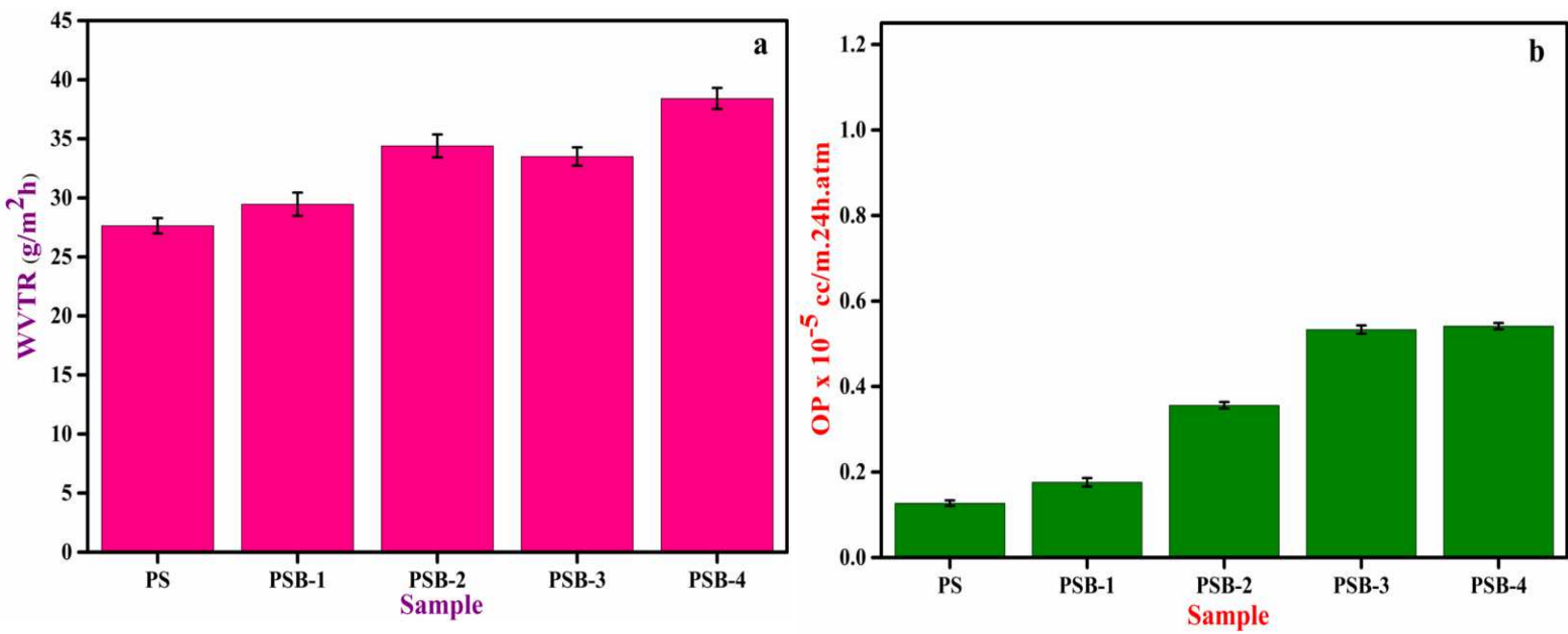

Figure 7. WVTR and OP of PS and PSB blend films.

The food packaging films must have the tendency to prevent the penetration of moisture in the film from the exterior environment. Determining WVTR is an important aspect in which moisture can pass through the film specimen and has an extreme effect on the food shelf life. Figure 7 (a) indicates the WVTR of PS blend and BLE incorporated blend films. The WVTR of PS blend films was $27.73 \mathrm{~g} / \mathrm{m}^{2} \mathrm{~h}$. However, blend films containing betel leaf extract can exhibit higher WVTR in contrast with control PS blend film. Generally, the WVTR depends on the hydrophilic and hydrophobic nature of the films. The enhancement in the WVTR of PSB blend films might be due to the increase in the polar groups in the blend solution also increased the moisture sensitivity of the films [45]. These results are also correlated with the decreased in the water contact angle and increased solubility of the PSB blend films which are discussed earlier.

Oxygen permeability is a criterion to indicate the penetration of oxygen through the film. The films with oxygen barrier properties can improve the quality and shelf life of the food [46]. The oxygen permeability of the BLE incorporated blend films as compare control PS blend films are shown in Figure 7(b). Apparently, the incorporation of BLE (2ml, 4ml, $6 \mathrm{ml}, 8 \mathrm{ml})$ in the PS blend increased the oxygen permeability of the films as compared to the control PS blend film. This fact might be due to the increase in the polar groups in the blend films enhances the moisture content of the films thus subsequently increased the oxygen permeability. The obtained results are associated with previously reported results by Nouri et al. $[25]$. 


\section{Scanning Electron Microscopy (SEM)}
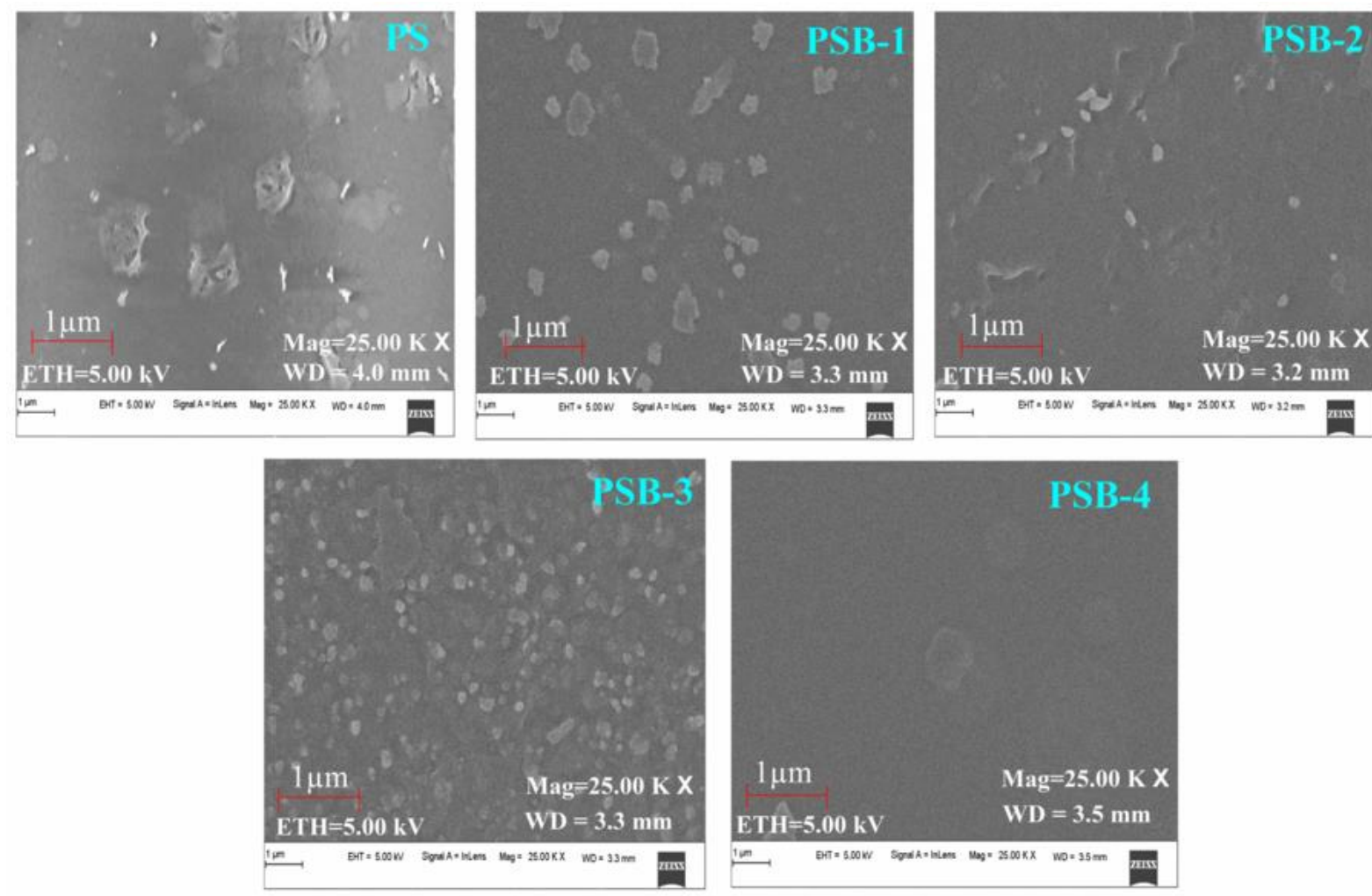

Figure 8. SEM micrographs of PS and PSB blend films.

SEM is an essential tool to figure out the morphological behaviour of the film surface. The surface images of PS and PSB blend films were presented in Figure 8. It can be observed that the PS blend film showed the heterogeneous surface with an agglomeration of OMS particles containing several unequalized pores. The results are well consistent with other researchers, suggested that weak compatibility and miscibility led to rougher surface morphology $[47,13]$. The structural variation takes place with the incorporation of BLE into PS matrix, exhibited the change in surface morphology of PSB blend that observed based on the concentration of BLE. At the lower concentration of BLE film presented the irregular shapes with an agglomeration of BLE content along with white patches of OMS. Further, the patches OMS were reduced by the increasing the amount of BLE in the blend. From the surface morphology of all the blend films, it can be seen that the PSB-4 blend film exhibited a smoother surface. This outcome demonstrates that the inclusion of the BLE in the PS matrix enhances the compatibility, indicating the strong hydrogen bonding interaction occurred among the polar groups of PVA, OMS and BLE [48-49]. However the PSB-3 blend film presented the rougher surface morphology, this can be attributed to the poor compatibility 
between the components of the blend films. The SEM results are in good relevance with the result of FTIR, WCA and Solubility studies.

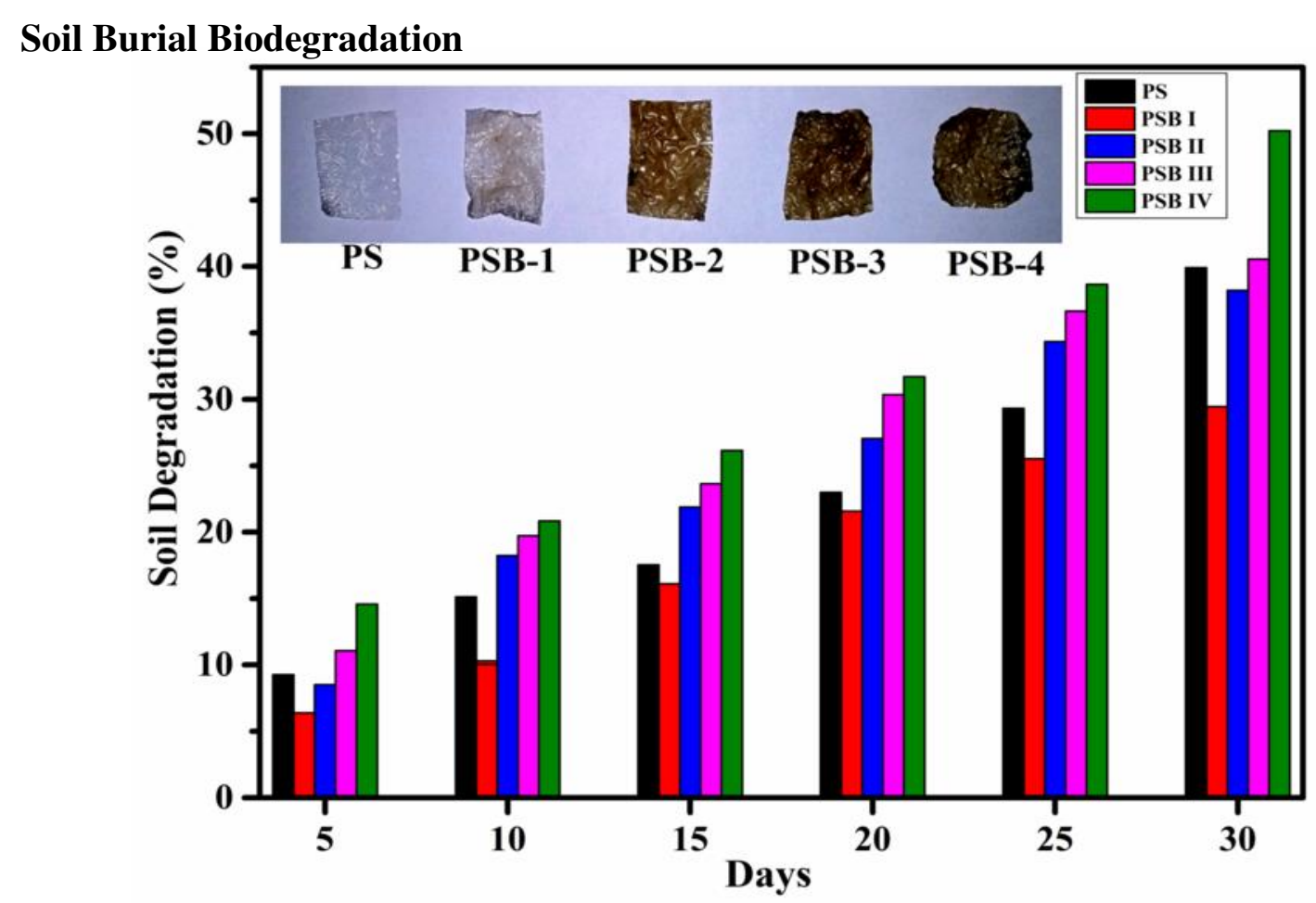

Figure 9: Soil Degradation (\%) of prepared films.

The effect of BLE on the biodegradation of PS blend films was studied by employing soil burial test at laboratory condition. The degradation (\%) of all the samples was calculated by evaluating the mass loss of the samples over time for 30 days and outcomes are presented in Figure 9. The PS blend film exhibited the well degradation rate due to the easier attack of microorganisms on OMS [50].---The embodiment of BLE accelerates the degradation rate of the PS blend films and all the PSB blend films presented elevated degradation percentages as compare to control PS blend films. This can be attributed to the extreme degradation of small molecules of BLE and highly solubility of the films in water as explained in the solubility test. Similar findings were reported by Carolina $\boldsymbol{M} \boldsymbol{J}$ et al [51] and explained that the addition of yerba mate extract enhanced the biodegradability of starch-glycerol films. The prepared PSB films are a promising material to safeguard the environment.

\section{Differential Scanning Calorimetry (DSC)}

The assessment of a single glass transition temperature $\left(T_{\mathrm{g}}\right)$ for a blend film is considered as an indication of polymer miscibility of all the components in the film [52]. The DSC thermograms achieved for the PS and PSB blend films are exposed in Figure 10. The values of $T_{g}, T_{m}, \Delta H_{m}$ and $X_{c}$ are collected in Table 4. The control PS blend film exhibited $T_{g}$ at $95.64{ }^{\circ} \mathrm{C}$. The incorporation of BLE into PS blend enhanced the $\mathrm{T}_{\mathrm{g}}$ as the content of BLE 
increased up to certain dopant level but the reduction in the $T_{g}$ values was observed at a higher dopant level. The increment in the $T_{g}$ values of PSB blend films indicates that the reinforcement of BLE into PS miscible over a certain composition will restrict the motion of polymer chain and decrease in the interaction between components reduced the $\mathrm{T}_{\mathrm{g}}$ of the PSB blend films at higher dopant level. Similar results were reported by other researchers [53-54].

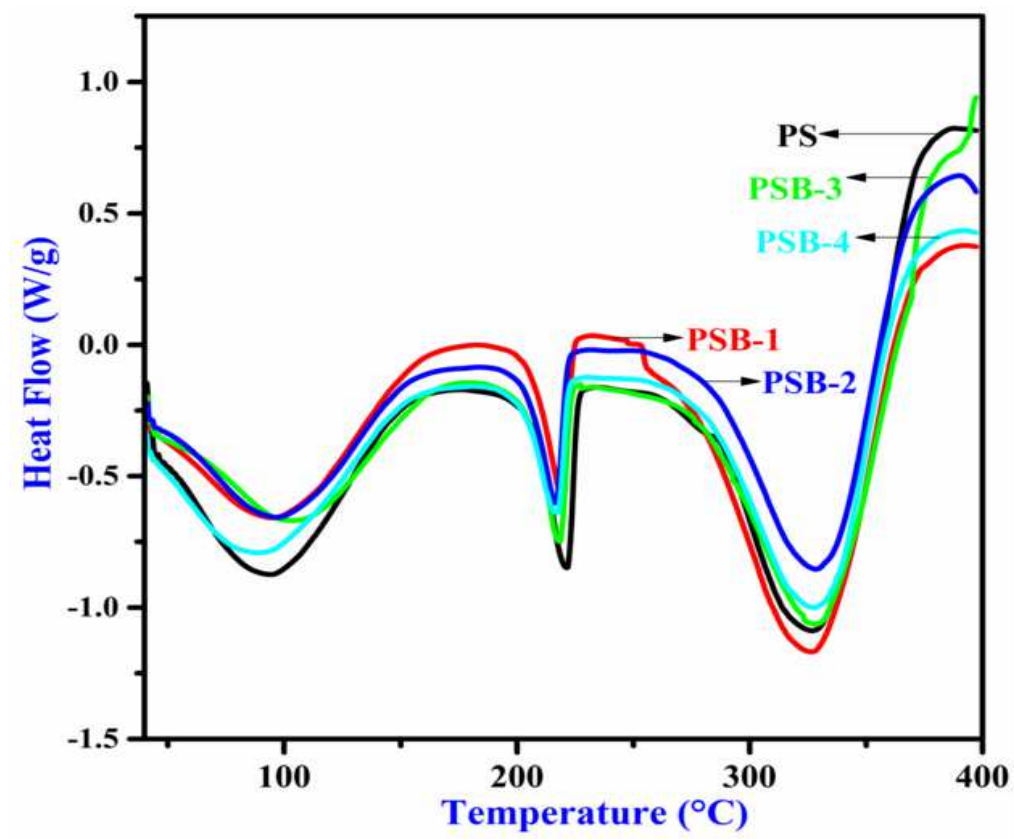

Figure 10: DSC Thermograms of prepared films.

Meanwhile, the $T_{m}$ and $T_{d}$ values of the PSB films were not so much altered. However, the melting enthalpy $\left(\Delta \mathrm{H}_{\mathrm{m}}\right)$ of PSB composite films was reduced as compared to control PS blend films. Meanwhile, the addition of BLE in the PS blend films results in lowering the $X_{c}$ indicating the amorphous structure of PSB composite films [32].

Table 4. $T_{g}, T_{m}$ and $T_{d}$ values of PS and PSB blend films.

\begin{tabular}{cccccc}
\hline Sample Code & $\mathrm{T}_{\mathrm{g}}\left({ }^{\circ} \mathrm{C}\right)$ & $\mathrm{T}_{\mathrm{m}}\left({ }^{\circ} \mathrm{C}\right)$ & $\mathrm{T}_{\mathrm{d}}\left({ }^{\circ} \mathrm{C}\right)$ & $\Delta \mathrm{H}_{\mathrm{m}}\left(\mathrm{Jg}^{-1}\right)$ & $\mathrm{X}_{\mathrm{c}}(\%)$ \\
\hline PS & 95.64 & 221.52 & 329.49 & 54.96 & 35.69 \\
PSC-1 & 96.59 & 219.48 & 327.85 & 43.75 & 30.84 \\
PSC-2 & 98.66 & 216.81 & 329.80 & 41.20 & 32.25 \\
PSC-3 & 93.53 & 217.40 & 329.09 & 40.37 & 37.70 \\
PSC-4 & 77.35 & 224.12 & 299.01 & 42.67 & 30.78 \\
\hline
\end{tabular}

$\mathrm{T}_{\mathrm{g}}$ - Glass Transition temperature, $\mathrm{T}_{\mathrm{m}}$-Melting Temperature, $\mathrm{T}_{\mathrm{d}}$-Degradation Temperature, $\Delta \mathrm{H}_{\mathrm{m}}-\mathrm{Melting}$ Enthalpy, $\mathrm{X}_{\mathrm{c}}$ - Percentage Crystallanity.

\section{Thermogravimetric Analysis (TGA)}

The TGA analysis was carried out to assess the outcomes of the incorporation of BLE on the thermal stability of the blend films. The thermal evolution of PSB, PS blend in the form of TGA curve is shown in Figure 11. The TG curve of all the films illustrates three consecutive 
transitions in their thermal degradation and respected weight losses are tabularized in Table 5. In the thermal event of PS blend film represents the first weight loss (12.00\%) film shown first weight loss $(11.71 \%)$ at the range of $103-116{ }^{\circ} \mathrm{C}$ this could be attributed to the defeat of water content of the blend films. The second massive weight loss (74.94\%) occurred at 279$359{ }^{\circ} \mathrm{C}$ represents the degradation of polyvinyl alcohol and OMS molecules via dehydration of the $\mathrm{OH}$ group. The third thermal decomposition is located in the temperature range of 359$455{ }^{\circ} \mathrm{C}(8.22 \%)$ this corresponds to cleavage of polymeric backbone or carbonisation. The related results were reported by other researchers [55-56].
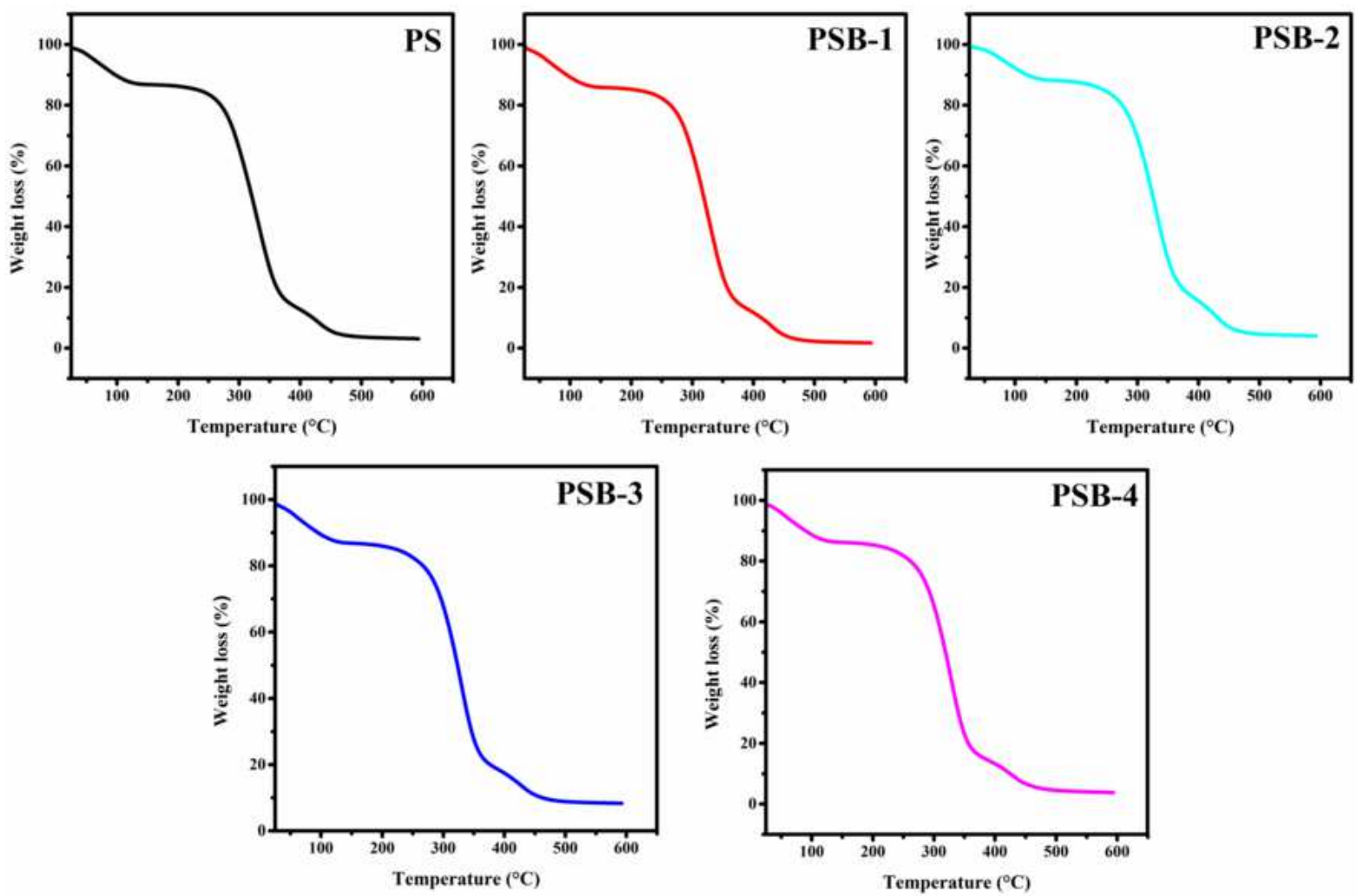

Figure 11: TGA Thermograms of prepared films.

The BLE incorporated blend films also exhibit three step decomposition pattern with three successive mass losses. The initial weight loss (10.89-12.89\%) observed in the temperature range between $25-126{ }^{\circ} \mathrm{C}$ attributes to the defeat of physically connected water molecule. The maximum and second massive weight loss (70.03-73.95\%) in the temperature range between $280-356{ }^{\circ} \mathrm{C}$ related to the degradation of PVA, OMS and BLE, involves the parallel process of destruction of three components. The final mass loss (7.87-10.72\%) occurred in the temperature range of $419-457^{\circ} \mathrm{C}$. These results demonstrate that the PSB films are thermally more stable when compared with PS blend films. The enhancement in the thermal stability may due to the hydrogen bonding interaction of BLE with PVA and OMS 
confirmed from FTIR, which hinders the mobility, diminish a segmental movement, as a result a additional energy required to degrade the polymer chain [57-58].

Table 5. Thermal properties prepared blend films.

\begin{tabular}{|c|c|c|c|c|c|c|}
\hline \multirow[b]{2}{*}{ Sample Code } & \multicolumn{2}{|c|}{ Step I } & \multicolumn{2}{|c|}{ Step II } & \multicolumn{2}{|c|}{ Step III } \\
\hline & Degradation & $\begin{array}{c}\text { Weight loss } \\
(\%)\end{array}$ & Degradation & $\begin{array}{c}\text { Weight loss } \\
(\%)\end{array}$ & Degradation & $\begin{array}{c}\text { Weight loss } \\
(\%)\end{array}$ \\
\hline PS & $116^{\circ} \mathrm{C}$ & 12.00 & $279-359^{\circ} \mathrm{C}$ & 74.94 & $359-455^{\circ} \mathrm{C}$ & 8.22 \\
\hline PSB - 1 & $116^{\circ} \mathrm{C}$ & 12.54 & $280-354{ }^{\circ} \mathrm{C}$ & 73.95 & $420-454{ }^{\circ} \mathrm{C}$ & 9.73 \\
\hline PSB - 2 & $126^{\circ} \mathrm{C}$ & 10.89 & $284-356^{\circ} \mathrm{C}$ & 73.07 & $420-455^{\circ} \mathrm{C}$ & 10.72 \\
\hline PSB - 3 & $111^{\circ} \mathrm{C}$ & 11.62 & $287-352^{\circ} \mathrm{C}$ & 70.03 & $424-457^{\circ} \mathrm{C}$ & 7.87 \\
\hline PSB - 4 & $107^{\circ} \mathrm{C}$ & 12.84 & $285-351^{\circ} \mathrm{C}$ & 72.39 & $419-457^{\circ} \mathrm{C}$ & 9.26 \\
\hline
\end{tabular}

\section{Antibacterial Activity}

The inclusion of antimicrobial agent into packaging film can extends the shelf life of food by inhibiting the microbes [59]. Strains that are susceptible to disinfectants reveal a larger zone inhibition diameter, while resistant strains exhibit a minor diameter of zone of inhibition [60]. The antibacterial activity of control PS blend and BLE doped PVA/OMS blend films were performed against the Escherichia coli and Staphylococcus aureus, representative of gram negative and gram positive bacteria and respected images are shown in Figure 12.
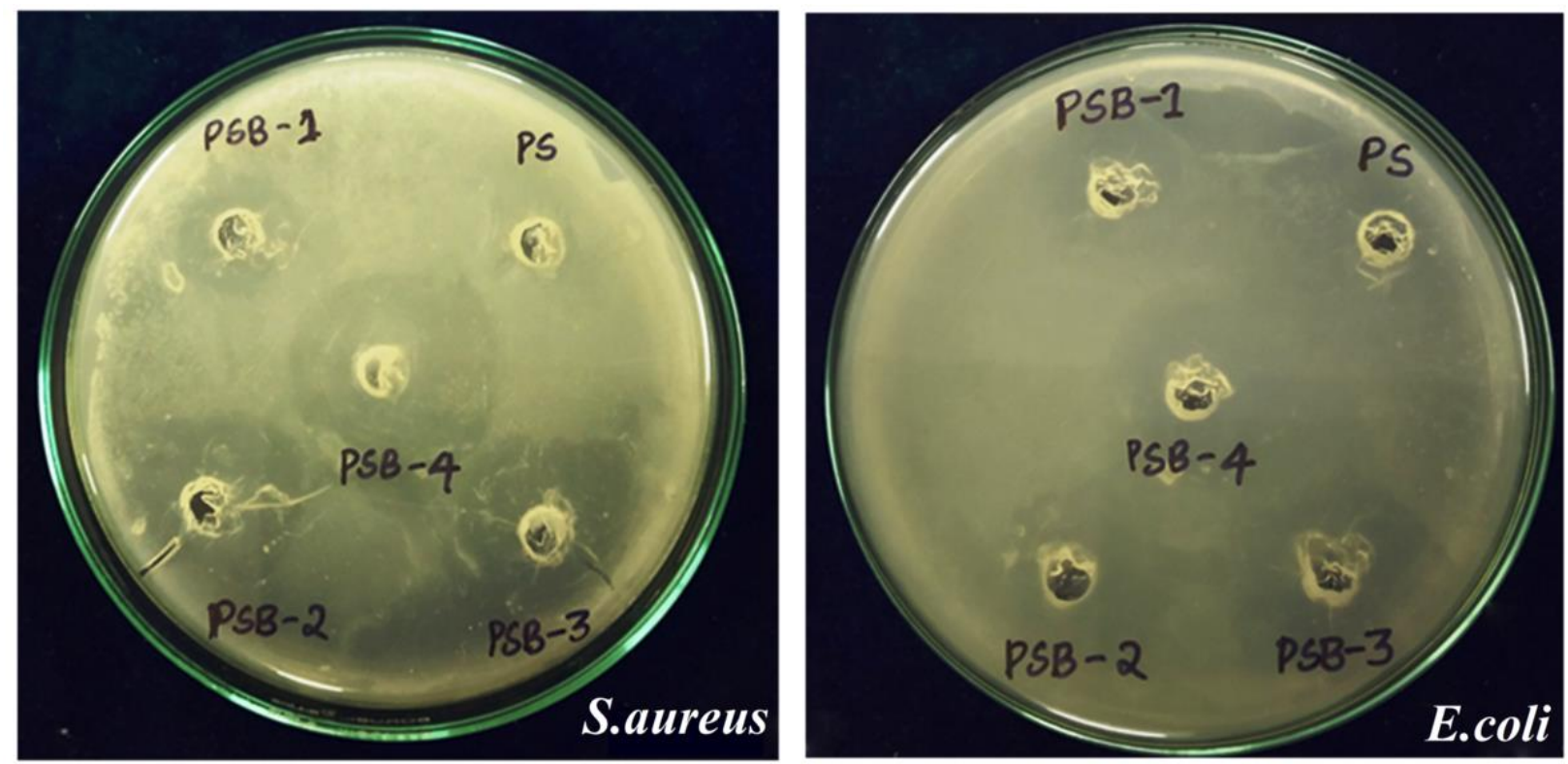

Figure 12: The Images of the antibacterial activity of PS and PSB blend films against $E$ coli and $S$ aureus.

By observing the image we can conclude that the PS blend films does not exhibit antimicrobial activity against both the bacterial strain. Similar results were reported by other researchers [61-62]. The addition of BLE caused to improve the antibacterial properties of PS 
blend films significantly and it is increased as the volume of BLE increase in the blend matrix. This outcome is on par with the research of Panuwat et al [63]. However the PSB blend films exhibited good antibacterial activity against gram positive bacteria as compare gram negative strain. This difference in zone inhabitation occurs due to the morphological variation of both the bacterial strain. The gram-negative organisms involves the phospholipidic membrane in the outer layer of their structure, thus makes a strong cell wall which is impermeable to the lipophilic solutes, whereas the gram positive bacteria are highly delicate due to surrounded by a peptidoglycan layer, which is not an efficient barrier [64].

Table 6. In vitro antibacterial activity of prepared blend films Samples Diameter of growth of inhibition zone (mm)

\begin{tabular}{ccc}
\cline { 2 - 3 } & S.aureus & E.coli \\
\hline PS & - & - \\
PSB-1 & $17.3 \pm 0.3$ & $16.3 \pm 0.57$ \\
PSB-3 & $20.2 \pm 0.34$ & $18.5 \pm 0.5$ \\
PSB-4 & $22.66 \pm 0.76$ & $21.6 \pm 0.52$ \\
& $26.6 \pm 0.52$ & $24.10 \pm 0.36$ \\
\hline
\end{tabular}

\section{DPPH radical scavenging activity}

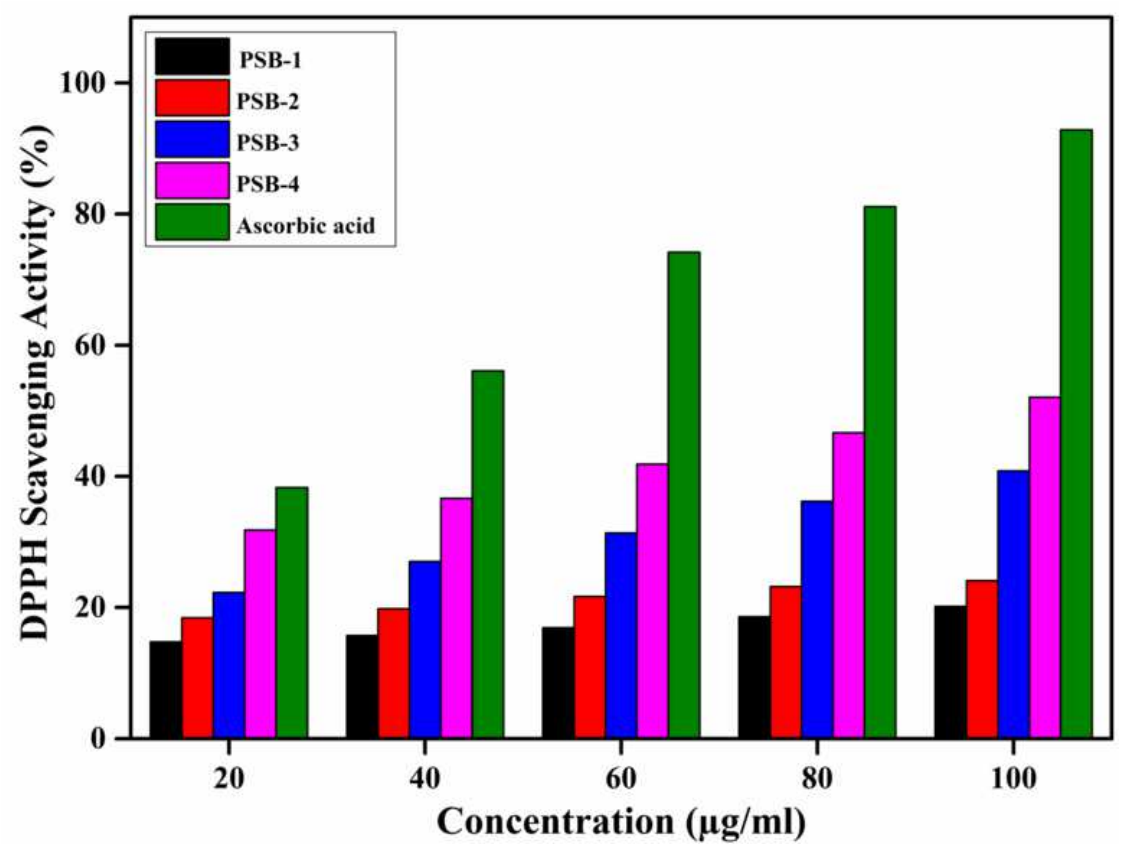

Figure 13: The DPPH scavenging activity PSB blend.

Antioxidant properties of BLE doped blend films were evaluated by diphenylpicrylhydrazine (DPPH) radical scavenging assay. DPPH is stable dark violet colour solution at $517 \mathrm{~nm}$ absorbance, changed to yellow colour by reacting with antioxidant substance that caused to 
reduce the absorbance with the formation of DPPH-H bonding [65]. Generally, the plant extracts involves the antioxidants like polyphenols exhibits the radical scavenging activity. The Figure 13 depicts the percentage savaging activity of the ascorbic acid and PSB blend films with respect to the concentration. The inclusion of BLE into the PS matrix revealed the notable antioxidant properties. Moreover the radical savaging activity increased with the increasing concentration of BLE in the PS blend. The improvement antioxidant activity is ascribed to flavonoid and phenolic content like hydroxyl chavicol present in the leaves. Similar trends were observed in the results reported by other researchers, suggested that maximum phenolic content revealed the higher radical scavenging activity [66-67].

\section{Conclusion}

Biodegradable polymers were broadly utilized to diminish the plastic wastes for ecological sustainability. Polyvinyl alcohol is a well-known synthetic biopolymer, successfully blended with oxidized maize starch and betel leaves extract to enhance the biodegradability and hence, reduce the cost of the material. The incorporation of BLE into PVA/OMS relatively improved the TS and EB at a lower concentration of BLE. The hydrogen bonding interaction among the functional groups of PVA, OMS and phenolic compounds of BLE, contributes to smooth and homogeneous surface morphology by reducing the patches of OMS particles. The DSC studies revealed the single glass transition temperature for all the blend films, confirmed the good miscibility between the components of the blend film. The thermal stability of the PSB blend films were greatly increased by the inclusion of BLE. The results obtained from optical properties suggested that UV light transmittance of PSB blend films declined as compared to control PVA/OMS film indicates PSB blend films have a good obstacle to UV light. Meanwhile, the barrier properties such as WVTR and OP of the films were increase as the concentration of BLE increased. The prepared blend films are hydrophilic in nature these finding were consistent with the increasing the water solubility since all the components used are hydrophilic materials. Consequently, all the blend films are biodegradable and exhibited good inhibitory activity against both the gram negative and gram positive bacterial strains. Moreover, the blend films revealed the excellent antioxidant properties. These experimental outcomes suggest that the PVA/OMS/BLE blend films have a capability for the expansion of active packaging material. 


\section{Acknowledgement}

The authors are grateful for instrumental facilities provided by University Scientific Instruments Centre (USIC), DST Sophisticated Analytical Instrument Facilities (SAIF), DST PURSE Phase II project (Program Grant No. SR/PURSE PHASE-2/13), Karnataka University, Dharwad, and Karnataka, India. The authors express their heartfelt gratitude to Mr. Mahantesh Kurbet, Manager, Quality Control Department, Millennium Starch India, Pvt. Ltd., Athani, Karnataka, India, for a generous gift of oxidized maize starch. We also wish to thank Dr. Saraswati P. Masti, Principal Investigator, DST-SERB Project, (project sanction letter No. SB/EMEQ-213/2014, dated: 29-01-2016), Department of Chemistry, Karnataka Science College, Dharwad, Karnataka, India, for providing Dak system Universal Testing Machine (UTM) to study the mechanical properties.

\section{References}

[1]. Yoon SD, Chough SH, Park HRY (2010) Preparation of Resistant Starch/Poly(vinyl alcohol) Blend Films with Added Plasticizer and Cross linking Agents. J.Appl.Polym.Sci.

https://doi.org/10.1002/app.26755.

[2]. Jayakumar A, Heera KV, Sumi TS, Joseph M, Mathew S, Praveen GB, Nair IC, Radhakrishnan EK (2019) Starch-PVA composite films with zinc-oxide nanoparticles and phytochemicals as intelligent $\mathrm{pH}$ sensing wraps for food packaging application. Int.J.Biol.Macromol. https://doi.org/10.1016/j.ijbiomac.2019.06.018

[3]. Ramesh M, Mitchell JR, Harding SE (1999) Amylose content of rice starch. Starch/Stärke.

https://doi.org/10.1002/(SICI)1521-379X(199909).

[4]. Lu DR, Xiao CM, Xu SJ (2009) Starch-based completely biodegradable polymer materials. EXPRESS Polym. Lett.

https://doi.org/10.3144/expresspolymlett.2009.46 
[5]. Kaseem M, Hamad K, Deri F (2012) Thermoplastic Starch Blends: A Review of Recent Works. Polymer Science Ser.A.

https://doi.org/10.1134/S0965545X1202006X

[6]. Zamudio-Flores PB, Vargas-Torres A, Pérez-González J, Bosquez-Molina E, BelloPérez LA (2006) Films Prepared with Oxidized Banana Starch: Mechanical and Barrier Properties. Starch/Stärke.

https://doi.org/10.1002/star.200500474.

[7]. Vanier NL, Halal SLME, Dias ARG, Zavareze EDR (2017) Molecular structure, functionality and applications of oxidized starches: A review. Food Chem. http://dx.doi.org/10.1016/j.foodchem.2016.10.138.

[8]. Kuakpetoon D, Wang YJ (2006) Structural characteristics and physicochemical properties of oxidized corn starches varying in amylose content. Carbohydr Res. https://doi.org/10.1016/j.carres.2006.04.013.

[9]. Pietrzyk S, Fortuna T (2005) Oxidation induced changes in the surface structure in the starch granule. Polish J. Food Nutr. Sci. 55,159-164.

[10]. Kuakpetoon D, Wang Y (2001) Characterization of different starches oxidized by hypochlorite. Starch/Starke.

https://doi.org/10.1002/1521-379X(200105)53:5<211::AID-STAR211>3.0.CO;2-M.

[11]. Hu G, Chen J, Gao J (2009) Preparation and characteristics of oxidized potato starch films. Carbohydr.Polym.

https://doi.org/10.1016/j.carbpol.2008.10.032.

[12]. Dao PH, Nam TT, Phuc MV, Hiep NA, Thanh TV, Vuong NT, Xuan DD (2017) Oxidized maize starch: characterization and effect of it on the biodegradable films. ii. infrared spectroscopy, solubility of oxidized starch and starch film solubility. Vietnam.J.Sci.Tech.

https://doi.org/10.15625/2525-2518/55/4/7919.

[13]. Tang S, Zou P, Xiong H, Tang H (2008) Effect of nano-SiO2 on the performance of starch/polyvinyl alcohol blend films. Carbohydr.Polym.

https://doi.org/10.1016/j.carbpol.2007.09.019. 
[14]. Abrahama A, Solomanb PA, Rejinib VO (2016) Preparation of Chitosan-Polyvinyl Alcohol Blends and Studies on Thermal and Mechanical Properties. Procedia Technology.

https://doi.org/10.1016/j.carbpol.2007.09.019.

[15]. Choo K, Ching YC, Chuah CH, Julai S, Liou NS (2016) Preparation and Characterization of Polyvinyl Alcohol-Chitosan Composite Films Reinforced with Cellulose Nanofiber. Materials. https://doi.org/10.3390/ma9080644.

[16]. Cruz RM, Alves V, Khmelinskii I, Vieira MC (2018) New food packaging systems. Food Packaging and Preservation. 63-85.

[17]. Tako M, Kerekes EB, Zambrano C, Kotogan A, Papp T, Krisch J, Vágvölgyi, C (2020) Plant Phenolics and Phenolic-Enriched Extracts as Antimicrobial Agents against Food-Contaminating Microorganisms. Antioxidants. https://doi.org/10.3390/antiox9020165.

[18]. Guha P (2006) Betel Leaf: The Neglected Green Gold of India, J. Hum. Ecol. https://doi.org/10.1080/09709274.2006.11905861.

[19]. Rathee JS, Patro BS, Mula S, Gamre S, and Chattopadhyay S (2006). Antioxidant Activity of Piper betel Leaf Extract and Its Constituents. J. Agric. Food Chem. https://doi.org/10.1021/jf061679e.

[20]. Ramji N, Iyer R, Chandrasekaran S (2002) Phenolic antibacterials from Piper betel in the prevention of halitosis. J.Ethnopharmacol. https://doi.org/10.1016/S0378-8741(02)00194-0.

[21]. Ambarta SP (1986) The Useful Plants of India; CSIR Publications: New Delhi, 4: 59.

[22]. Choudhury D, Kale RK (2002) Antioxidant and nontoxic properties of Piper betel leaf extract: In vitro and in vivo studies. Phytother. Res. 
https://doi.org/10.1002/ptr.1015.

[23]. Subramanian BS, Bauri M, Kamat A, Bandyopadhyay JP, Chattopadhyay SKS (2005) Radioprotecting property of the ethanolic extract of the Piper betel leaf. J. Radiat. Res.

https://doi.org/10.1269/jrr.46.165.

[24]. Datta A, Ghoshdastidar S, Singh M (2011) Antimicrobial Property of Piper betel Leaf against Clinical Isolates of Bacteria. Int.J.Pharm.Sci .Res. 2:104-109.

[25]. Nouri L, Nafchi AM (2014) Antibacterial, mechanical, and barrier properties of sago starch film incorporated with betel leaves extract. Int. J. Biol. Macromol. https://doi.org/10.1016/j.ijbiomac.2014.02.044

[26]. Kanatt SR, Rao MS, Chawla SP, Sharma A (2012) Active chitosan-polyvinyl alcohol films with natural extracts. Food.Hydrocoll.

https://doi.org/10.1016/j.foodhyd.2012.03.005.

[27]. Hiremani VD, Sataraddi S, Bayannavar PK, Gasti T, Masti SP, Kamble RR, Chougale RB (2020) Mechanical, optical and antioxidant properties of 7-Hydroxy-4-methyl coumarin doped polyvinyl alcohol/oxidized maize starch blend films. SN Applied Sciences.

https://doi.org/10.1007/s42452-020-03399-2

[28]. Yadav S, Mehrotra GK, Bhartiya P, Singh A, Dutta PK (2020) Preparation, physicochemical and biological evaluation of quercetin based chitosan-gelatin film for food packaging. Carbohydr.Polym.

https://doi.org/10.1016/j.carbpol.2019.115348.

[29]. Kaya M, Khadem S, Cakmak YS (2018) Antioxidative and antimicrobial edible chitosan films blended with stem, leaf and seed extracts of Pistacia terebinthus for active food packaging. RSC Adv. 8:3941-3950. 
[30]. Siripatrawan U, Harte BR (2010) Physical properties and antioxidant activity of an active film from chitosan incorporated with green tea extract. Food.Hydrocoll. doi:10.1016/j.foodhyd.2010.04.003.

[31]. Popescu MC, Dogaru BI, Goanta M, Timpu D (2018) Structural and morphological evaluation of CNC reinforced PVA/ Starch biodegradable films. Int. J. Biol. Macromol.

https://doi.org/10.1016/j.ijbiomac.2018.05.036.

[32]. Kasai D, Chougale R, Masti S, Chalannavar R, Malabadi RB, Gani R, Gouripur, G (2019) An Investigation into the Influence of Filler Piper nigrum Leaves Extract on Physicochemical and Antimicrobial Properties of Chitosan/Poly (Vinyl Alcohol) Blend Films. J. Polym.Environ.

https://doi.org/10.1007/s10924-018-1353-X.

[33]. Tang X, Alav S (2011) Recent advances in starch, polyvinyl alcohol based polymer blends, nanocomposites and their biodegradability. Carbohydr.Polym. https://doi:10.1016/j.carbpol.2011.01.030.

[34]. Das K, Ray D, Bandyopadhyay NR, Sahoo S, Amar K, Misra MM (2011) Physicomechanical properties of the jute micro/nanofibril reinforced starch/polyvinyl alcohol biocomposite films. Composites: PartB.

https://doi:10.1016/j.compositesb.2010.12.017.

[35]. Jianga X, Jianga T, Gana L, Zhanga X, Dai H, Zhanga X (2012) The plasticizing mechanism and effect of calcium chloride on starch/poly(vinyl alcohol) films. Carbohydr.Polym. 90:1677-1684.

[36]. Bourtoom T, Chinnan SM (2008) Preparation and properties of rice starch-chitosan blend biodegradable film. LWT - Food Science and Technology. https:// doi:10.1016/j.1wt.2007.10.014.

[37]. Hiremani V, Gasti T, Satareddi S, Vanjeri VN, Goudar N, Masti S, Chougale R. (2020) Characterization of Mechanical and Thermal Properties of Glycerol Mixed 
Oxidized Maize Starch/Polyvinyl alcohol Blend Films. Chemical Data Collections. https://doi.org/10.1016/j.cdc.2020.100416.

[38]. Cano A I, Chafer M, Chiralt A, Martinez CG (2015) Physical and microstructural properties of biodegradable films based on pea starch and PVA. J. Food Eng. http://dx.doi.org/10.1016/j.jfoodeng.2015.06.003.

[39]. Maizura M, Fazilah A, Norziah MH., Karim AA (2007) Antibacterial Activity and Mechanical Properties of Partially Hydrolyzed Sago Starch-Alginate Edible Film Containing Lemongrass Oil. J.Food Sci.

https://doi.org/10.1111/j.1750-3841.2007.00427.x.

[40]. Falguera V, Pagan J, Garza S, Garvin A, Ibarz A (2011) Ultraviolet processing of liquid food: A review Part 2: Effects on microorganisms and on food components and properties. Food Res. Int.

https://doi doi:10.1016/j.foodres.2011.03.025.

[41]. Gomez-Guillena MC, Ihlb M, Bifanib V, Silvab A, Monteroa P (2007) Edible films made from tuna-fish gelatin with antioxidant extracts of two different murta ecotypes leaves. Food.Hydrocoll.

https://doi:10.1016/j.foodhyd.2006.08.006.

[42]. Ghaderia J, Hosseinia SF, Keyvanib N, Gómez-Guillén MC (2019) Polymer blending effects on the physicochemical and structural features of the chitosan/poly(vinyl alcohol)/fish gelatin ternary biodegradable films. Food.Hydrocoll. https://doi.org/10.1016/j.foodhyd.2019.04.021.

[43]. Yuan Y, and Lee TR (2013) Contact Angle and Wetting Properties. Springer Series in Surface Sciences.

https://doi.org/10.1007/978-3-642-34243-1_1.

[44]. Wang Y, Jiang L, Duan J, Shao SI (2013) Effect of the Carbonyl Content on the Properties of Composite Films Based on Oxidized Starch and Gelatin. J. Appl. Polym. Sci. 
https://doi.org/ 10.1002/APP.39493.

[45]. Hun JH, Cennadios A (2005) Edible films and coatings: a review. Innovations in Food Packaging. https://doi.org/10.1016/B978-012311632-1/50047-4.

[46]. Brody AL, Bugusu B, Han JH, Sand CK, Mchugh TH (2008) Innovative Food Packaging Solutions. J.Food.Sci. https://doi:10.1111/j.1750-3841.2008.00933.x

[47]. Ismail H, Zaaba NF (2011) Effect of Additives on Properties of Polyvinyl Alcohol (PVA)/Tapioca Starch Biodegradable Films, Polym Plast Technol Eng. https://doi.org/10.1080/03602559.2011.566241.

[48]. Guimaraes M, Botaro VR, Novack, KM, Teixeira FG, Tonoli GHD (2015) Starch/PVA-based nanocomposites reinforced with bamboonanofibrils. Ind Crops Prod.

https://doi.org/10.1016/j.indcrop.2015.03.014.

[49]. Singha AS, Priya B, Pathania D (2015) Cornstarch/poly(vinyl alcohol) biocomposite blend films: mechanical properties, thermal behavior, fire retardancy, and antibacterial activity. Int J Polym Anal Charact. 20:357-366.

[50]. Hejri Z, Seifkordi AA, Ahmadpour A, Zebarjad SM, Maskooki A (2013) Biodegradable starch/poly (vinyl alcohol) film reinforced with titanium dioxide nanoparticles. Int. J. Miner. Metall.

https://doi.org/10.1007/s12613-013-0827-z.

[51]. Jaramilloa CM, Gutierrezc TJ, Goyanesa S, Bernalb C, Fama L (2016) Biodegradability and plasticizing effect of yerba mate extract on cassava starch edible films. Carbohydr.Polym.

http://dx.doi.org/10.1016/j.carbpol.2016.05.025.

[52]. Lewandowska, K (2009) Miscibility and thermal stability of poly(vinyl alcohol)/chitosan mixtures. Thermochimica Acta.

http://dx.doi:10.1016/j.tca.2009.04.003. 
[53]. Huawen H, Xin JH, Hong H, Chan A, Liang H (2013) Glutaraldehyde-chitosan and poly (vinyl alcohol) blends, and fluorescence of their nano-silica composite films. Carbohydr.Polym.

https://doi.org/10.1016/j.carbpol.2012.08.038.

[54]. Levchik GF, Kun S, Levchik SV, Camino G, Wilkie CA (1999) The correlation between cross-linking and thermal stability: Cross-linked polystyrenes and polymethacrylates. Polym.Degrad.Stabil.

https://doi.org/10.1016/S0141-3910(99)00028-2.

[55]. Luo X, Li J, Lin X (2012) Effect of gelatinization and additives on morphology and thermal behavior of corn starch/PVA blend films. Carbohydr.Polym. http://dx.doi.org/10.1016/j.carbpol.2012.07.036.

[56]. Aydına AA, Ilberg V (2016) Effect of Different Polyol-Based Plasticizers on Thermal Properties of Polyvinyl Alcohol (PVA):Starch Blends Films. Carbohydr.Polym. https://doi.org/10.1016/j.carbpol.2015.08.093.

[57]. Ali A, Shahid MA, Hossain MD, Islam MN (2019) Antibacterial bi-layered polyvinyl alcohol (PVA)-chitosan blend nanofibrous mat loaded with Azadirachta indica (neem) extract. Int.J.Biol.Macromol. https://doi.org/10.1016/j.ijbiomac.2019.07.015.

[58]. Gulati K, Lal S, Diwan PK, Arora S (2019) Investigation of Thermal, Mechanical, Morphological and Optical Properties of Polyvinyl alcohol Films Reinforced with Buddha Coconut (Sterculia alata) Leaf Fiber. International Journal of Applied Engineering Research. 14:170-179.

[59]. Narasagoudr SS, Hegde VG, Vanjeri VN, Chougale RB, Masti SP (2020) Ethyl vanillin incorporated chitosan/poly(vinyl alcohol) active films for food packaging applications. Carbohydr.Polym.

https://doi.org/10.1016/j.carbpol.2020.116049 
[60]. Hussain AUZ, Khan ARAN (2016) Enhanced mechanical, thermal and antimicrobial properties of poly (vinyl alcohol)/graphene oxide/starch/silver nanocomposites films. Carbohydr.Polym.

http://dx.doi.org/10.1016/j.carbpol.2016.08.026 0144-8617.

[61]. Wu Z, Wu J, Peng T, Li Y, Lin D, Xing B, Li C, Yang Y, Yang L, Zhang L, Ma R, Wu W, Xiaorong L, Jianwu D, and Han G (2017) Preparation and Application of Starch/Polyvinyl Alcohol/Citric Acid Ternary Blend Antimicrobial Functional Food Packaging Films. Polymers.

https://doi.org/10.3390/polym9030102.

[62]. Akhavan A, Khoylou F, Ataeivarjovi E (2017) Preparation and characterization of gamma irradiated Starch/PVA/ZnO nanocomposite films. Radiation Physics and Chemistry.

http://dx.doi.org/10.1016/j.radphyschem.2017.02.057.

[63]. Suppakul P, Sanla-Ead N, Phoopuritham P, Kasetsart (2006) Journal - Natural Science. 40:91-100.

[64]. Arias ME, Gomez JD, Cudmani NM, Vattuone MA, Isla MI (2004) Life Sciences. 75:191-202.

[65]. Garrido-Miranda KA, Rivas BL, Perez-Rivera MA, Sanfuentes EA, Pena-Farfal C (2018) Antioxidant and antifungal effects of eugenol incorporated in bionanocomposites of poly- (3-hydroxybutyrate)-thermoplastic starch. LWT Food Sci Technol.

https://doi.org/10.1016/j.1wt.2018.08.046

[66]. Sarma C, Rasane P, Kaur S, Singh J, Singh J, Gat Y, Garba U, Kaur D, Dhawan K (2018) Antioxidant and antimicrobial potential of selected varieties of Piper betle $\mathrm{L}$ (Betel leaf). An Acad Bras Cienc.

https://doi.org/10.1590/0001-3765201820180285. 
[67]. Rintu D, Shinjini M, Kaustab M, Pramathadhip P, Umesh P S, and Banerjee ER (2015) Anti-oxidant and anti-inflammatory activities of different varieties of Piper leaf extracts (Piper betle L.). Nutr Food Sci.

https://doi.org/10.4172/2155-9600.1000415. 


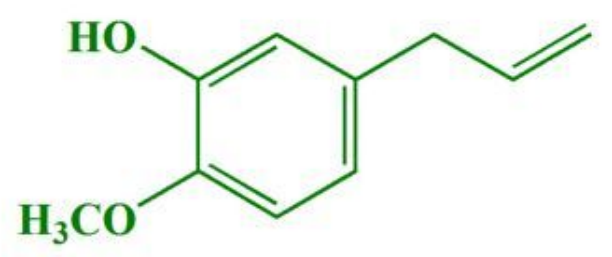

Chavibetol<smiles>C=CCc1ccc(O)c(O)c1</smiles>

Hydroxychavicol<smiles>C=CCc1ccc(O)c(OC)c1</smiles>

Eugenol

Figure 1

Representation of chemical components of betel leaf.
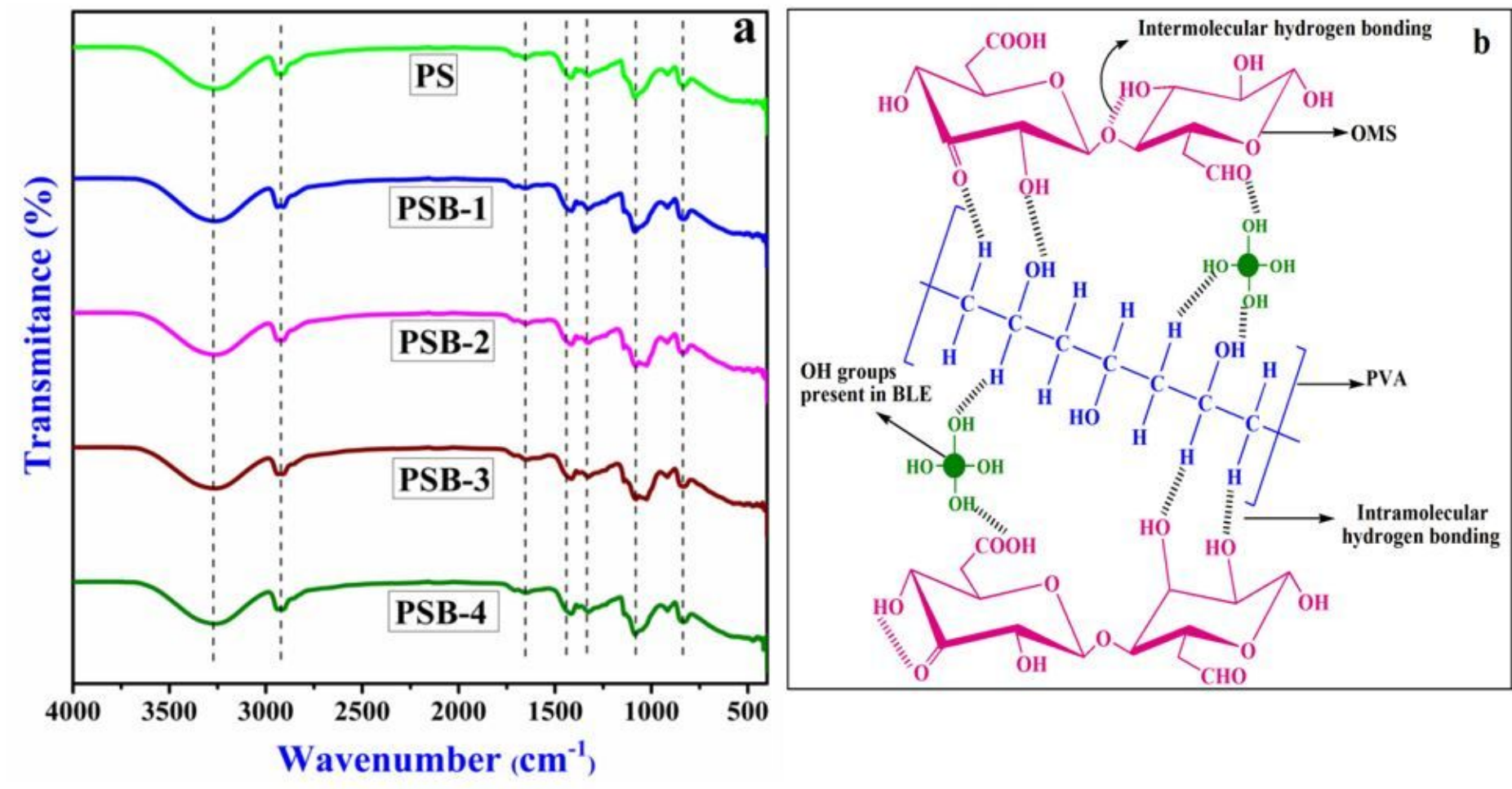

Figure 2

a) FTIR spectra of prepared blend films, b) Hydrogen bonding interaction between PVA, OMS and BLE. 

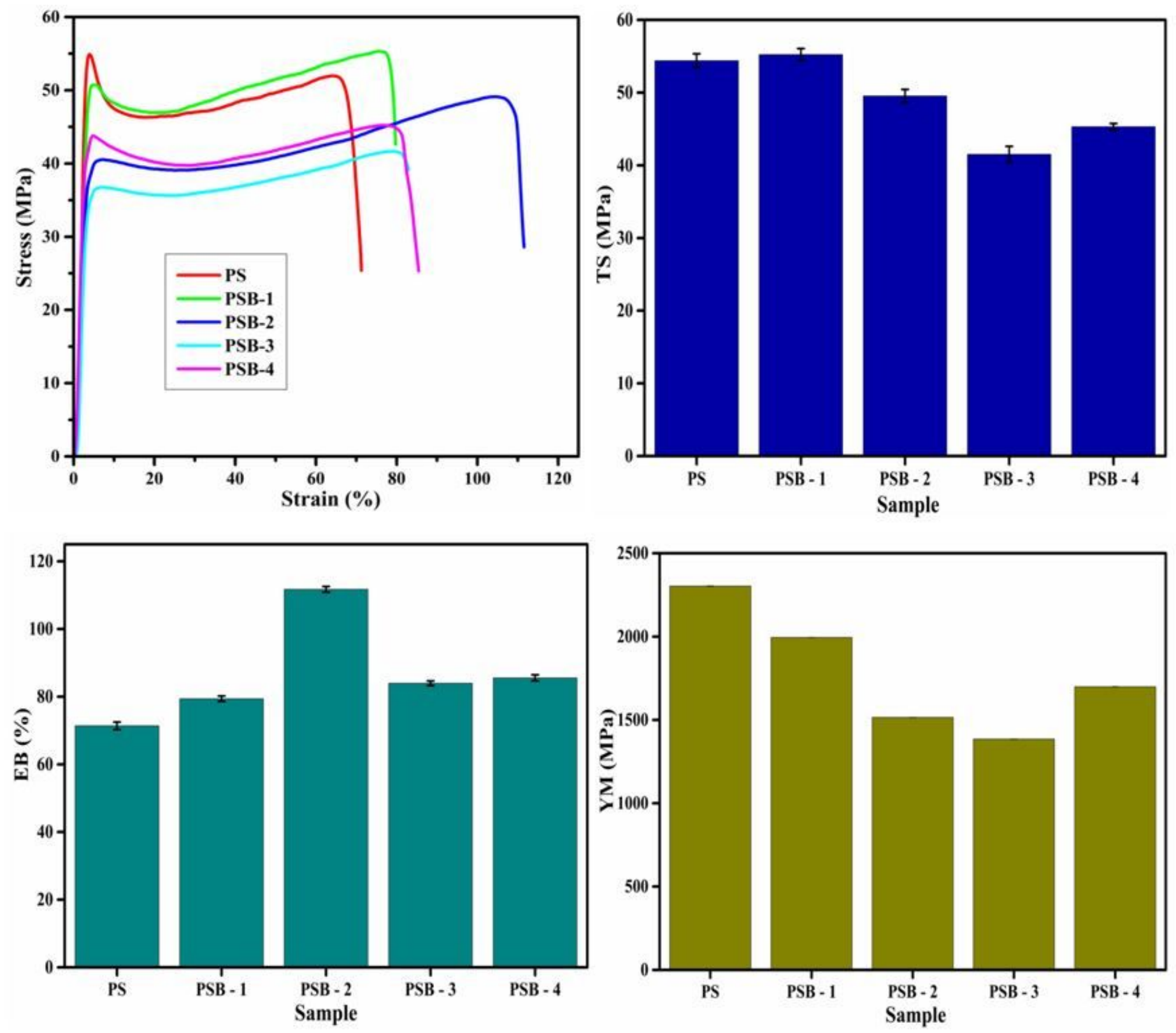

Figure 3

Mechanical properties of prepared blend films 


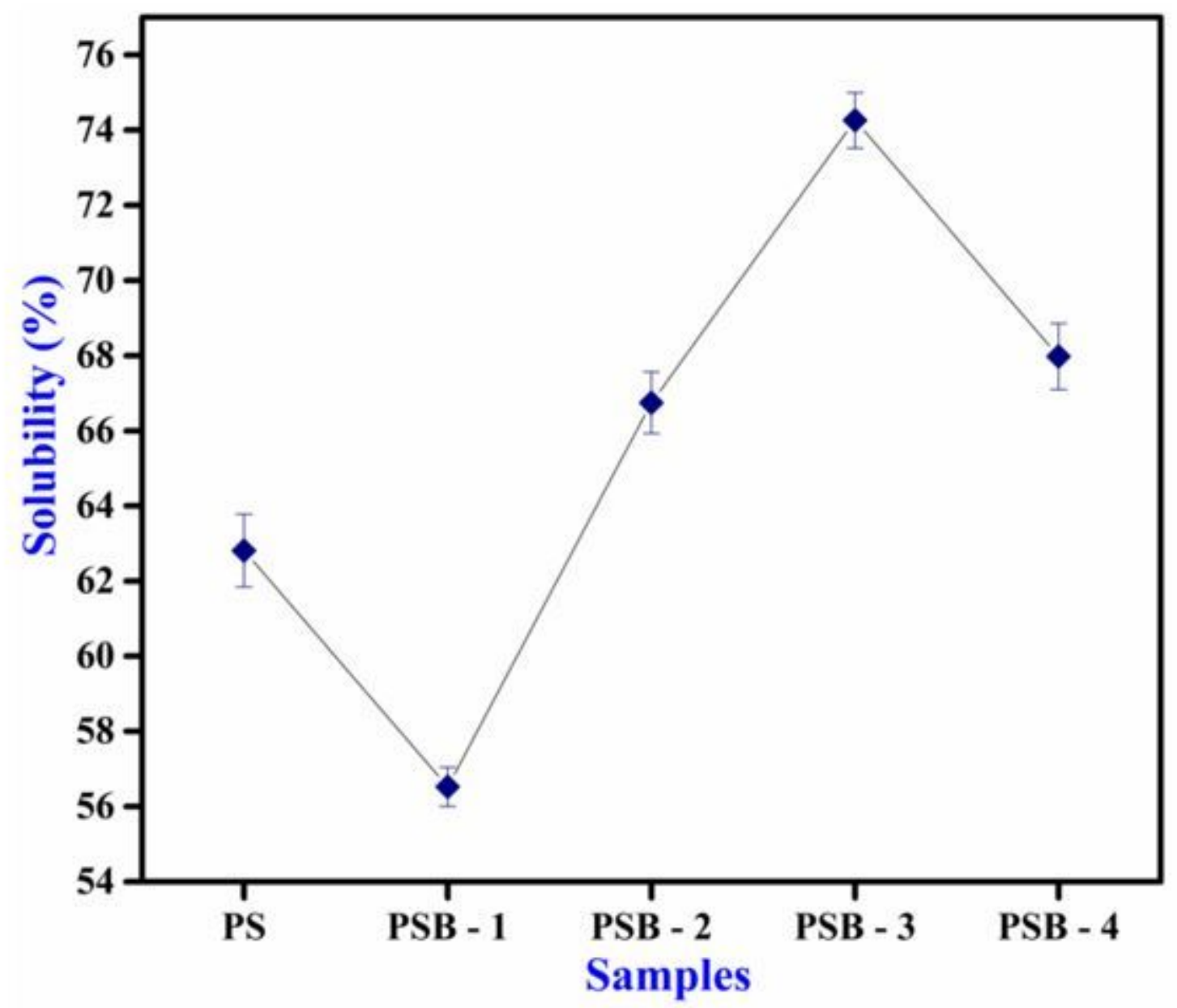

Figure 4

Solubility percentage of prepared blend films. 

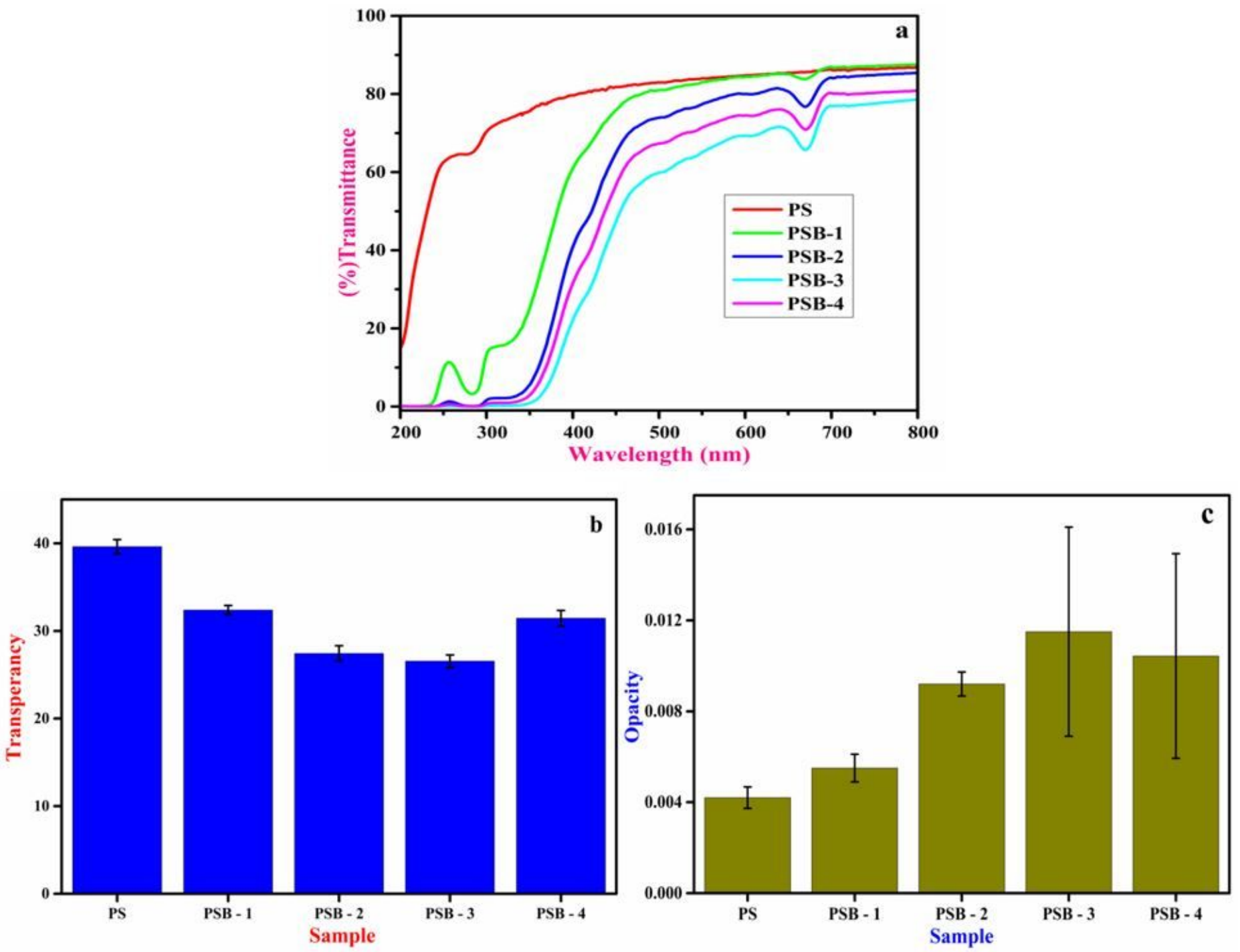

Figure 5

a) \% Transmittance, b) transparency and c) opacity of the prepared blend films 


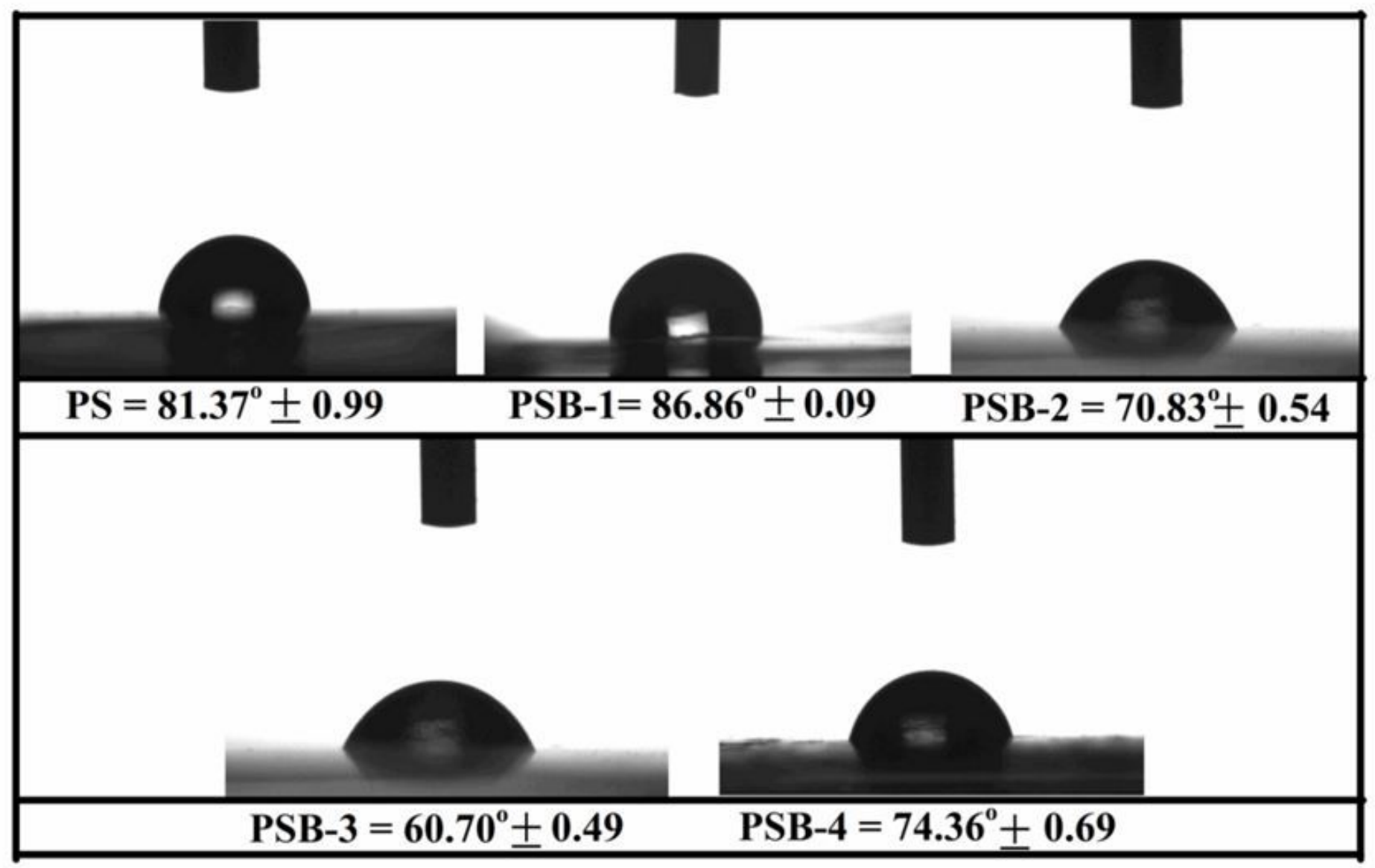

Figure 6

Water contact angle images of prepared blend films.
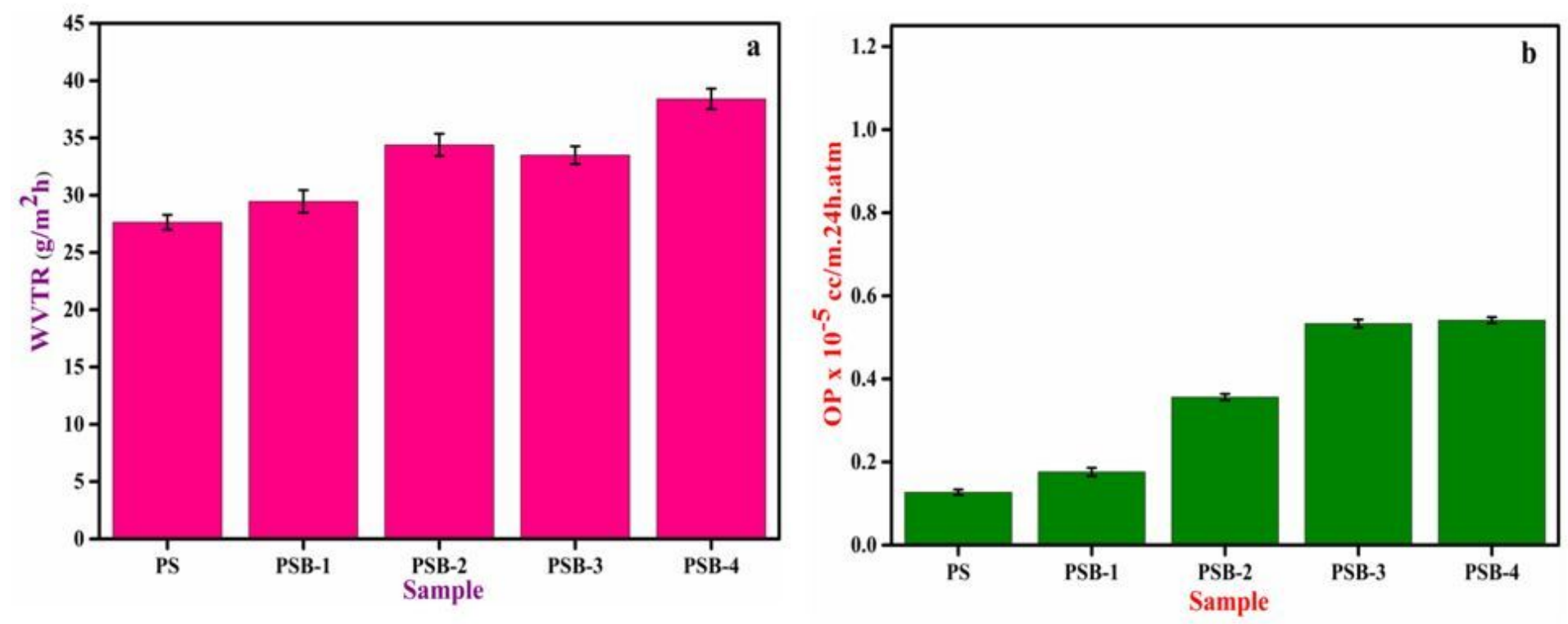

Figure 7 
WVTR and OP of PS and PSB blend films.
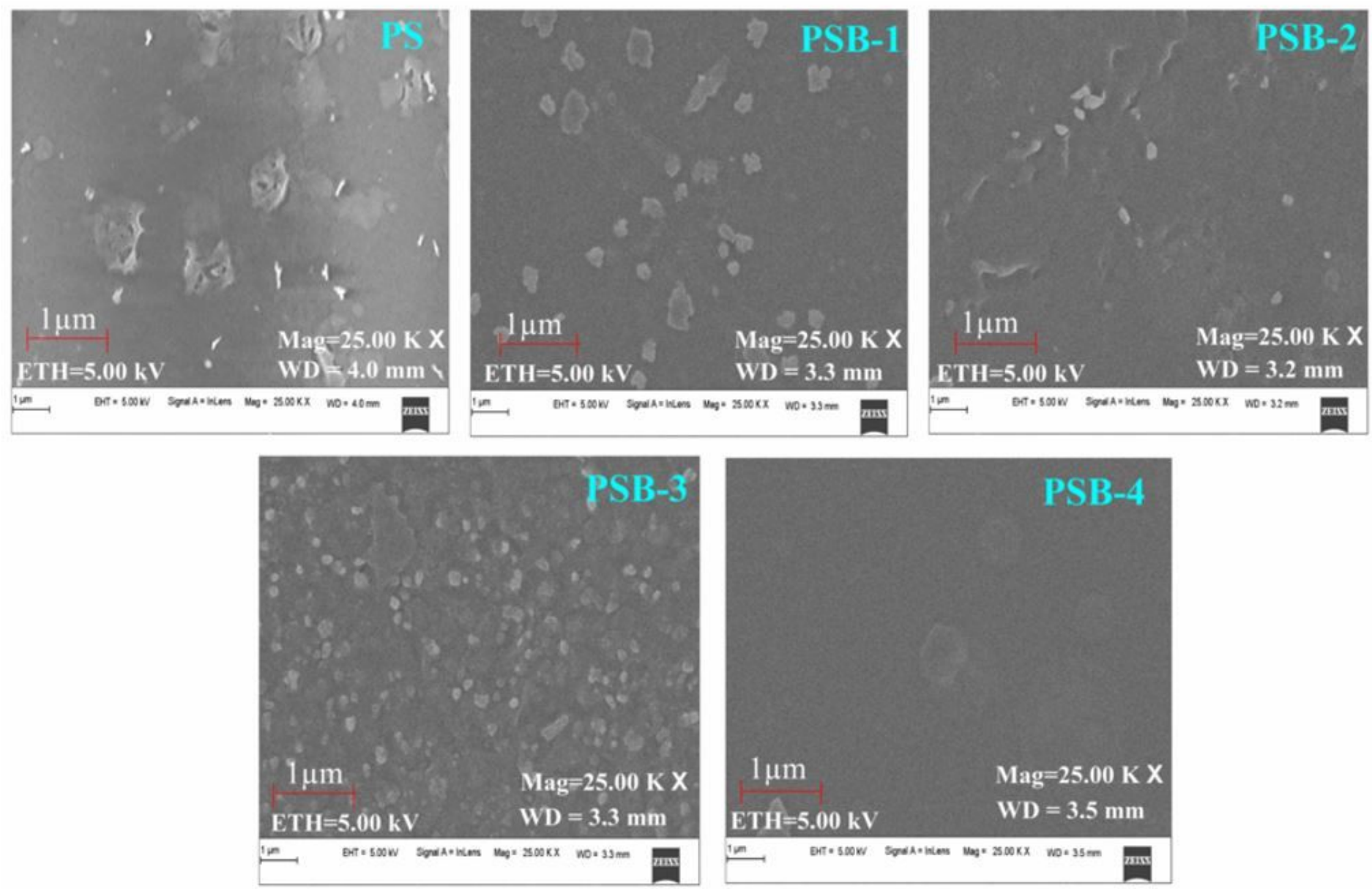

Figure 8

SEM micrographs of PS and PSB blend films. 


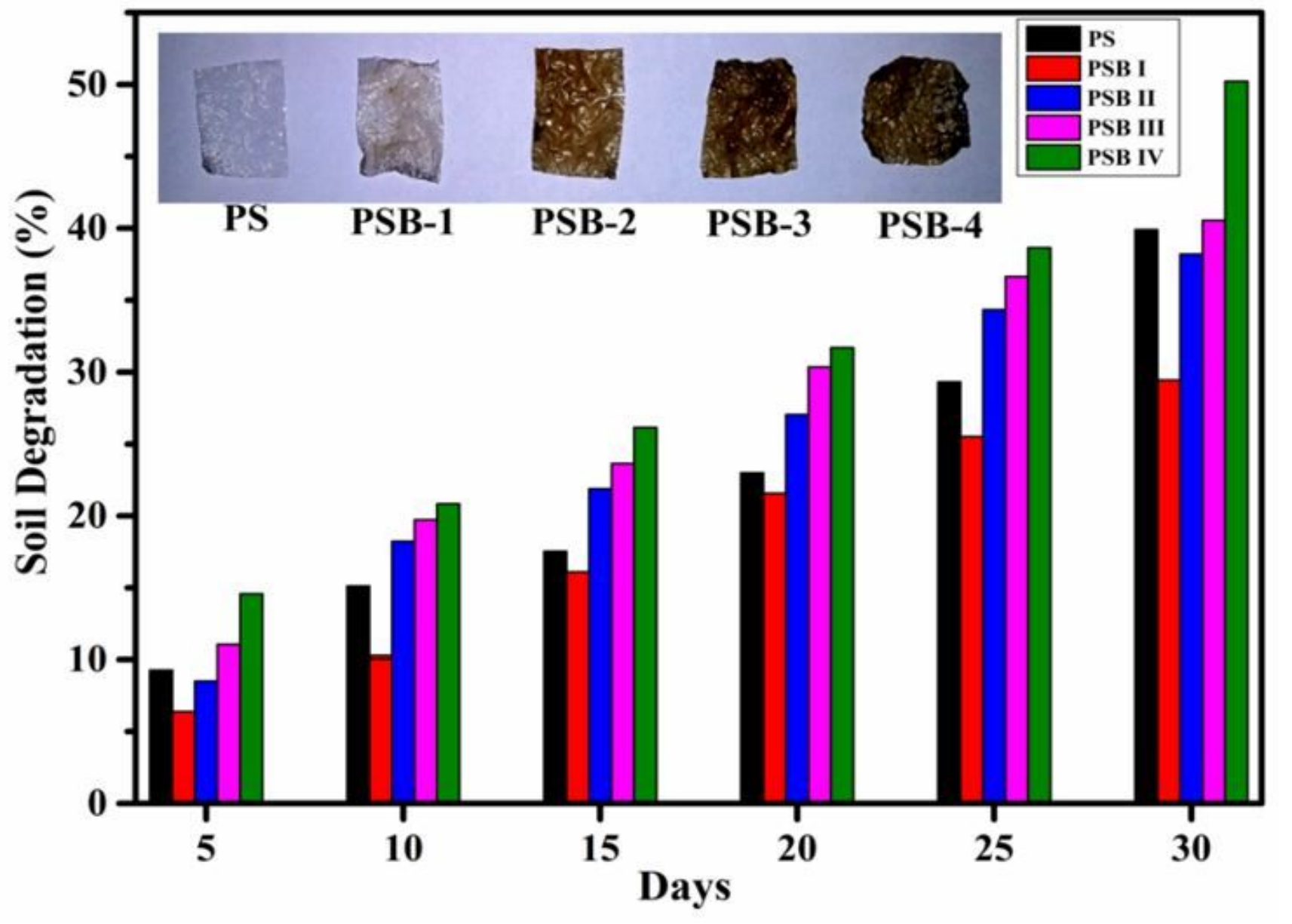

Figure 9

Soil Degradation (\%) of prepared blend films. 


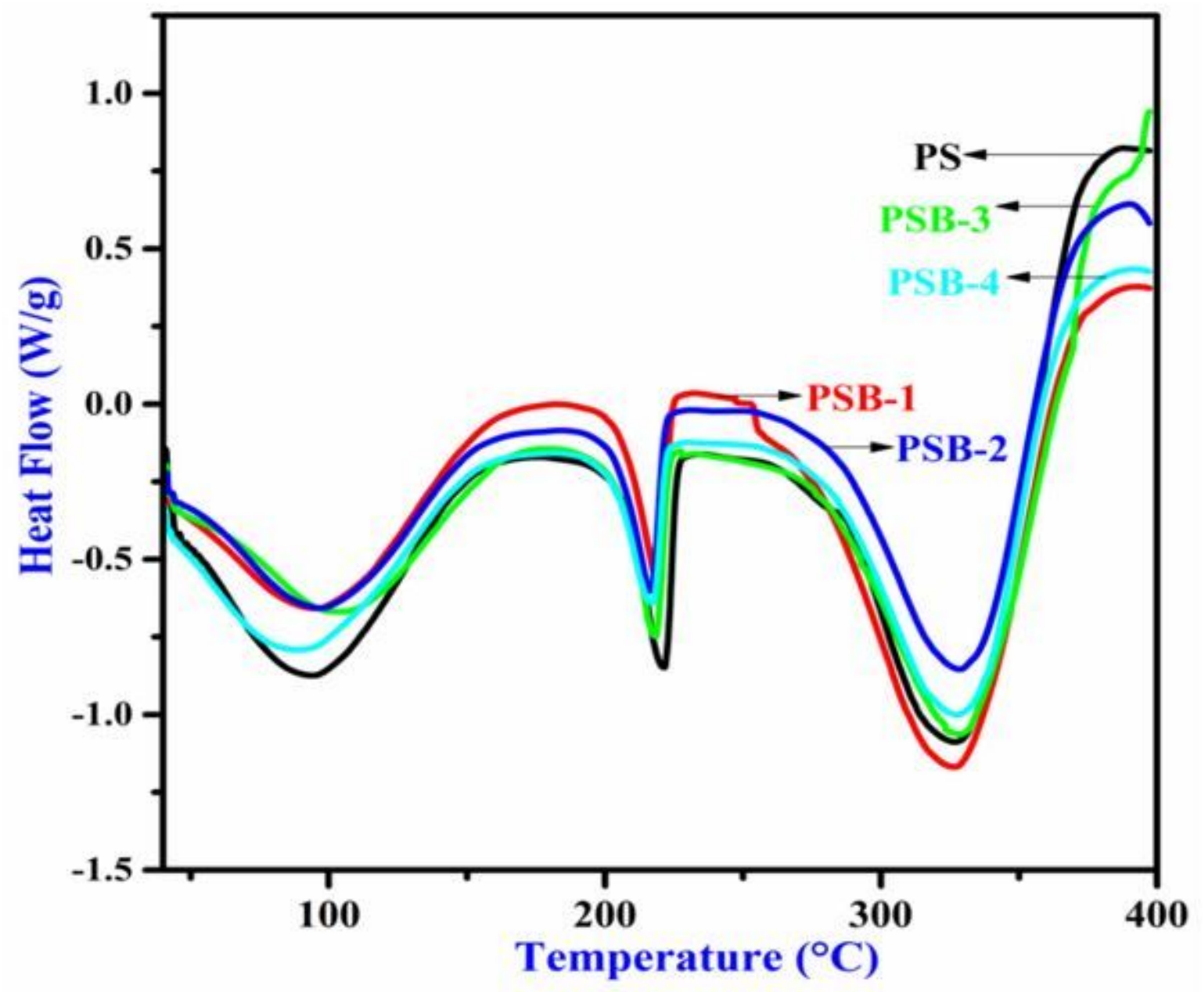

Figure 10

DSC Thermograms of prepared blend films. 

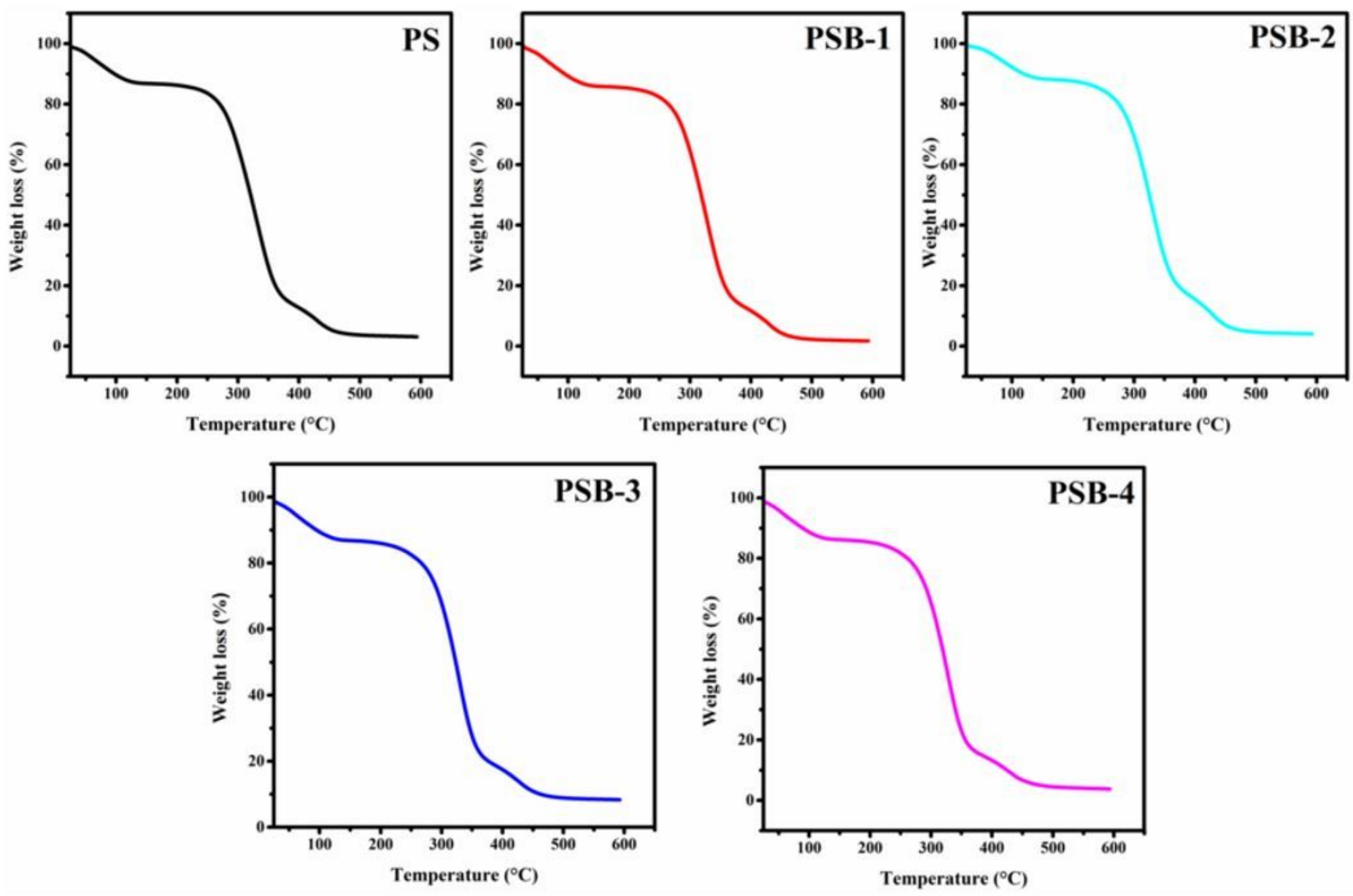

Figure 11

TGA Thermograms of prepared blend films. 

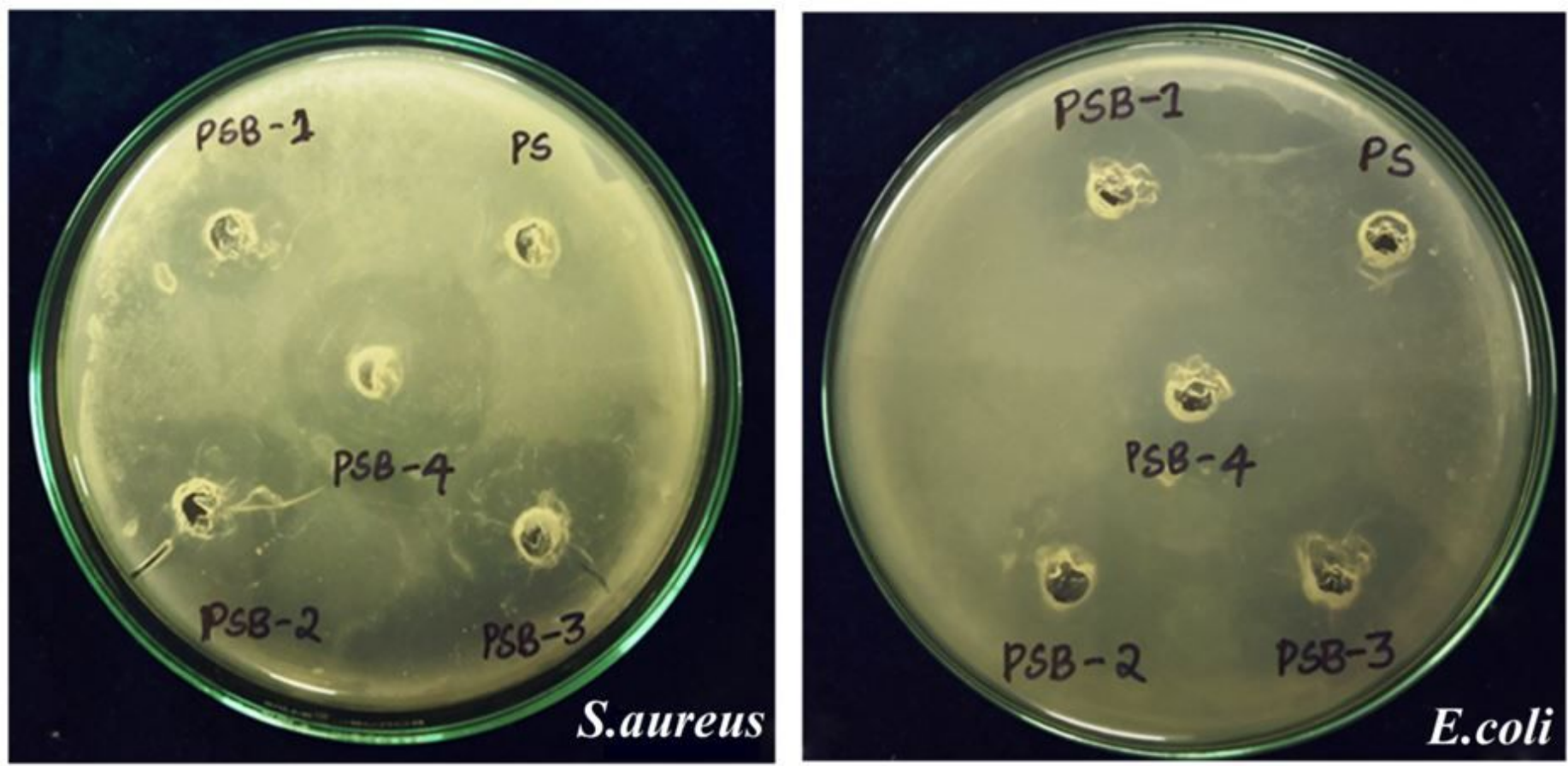

Figure 12

The Images of the antibacterial activity of PS and PSB blend films against E coli and S aureus. 


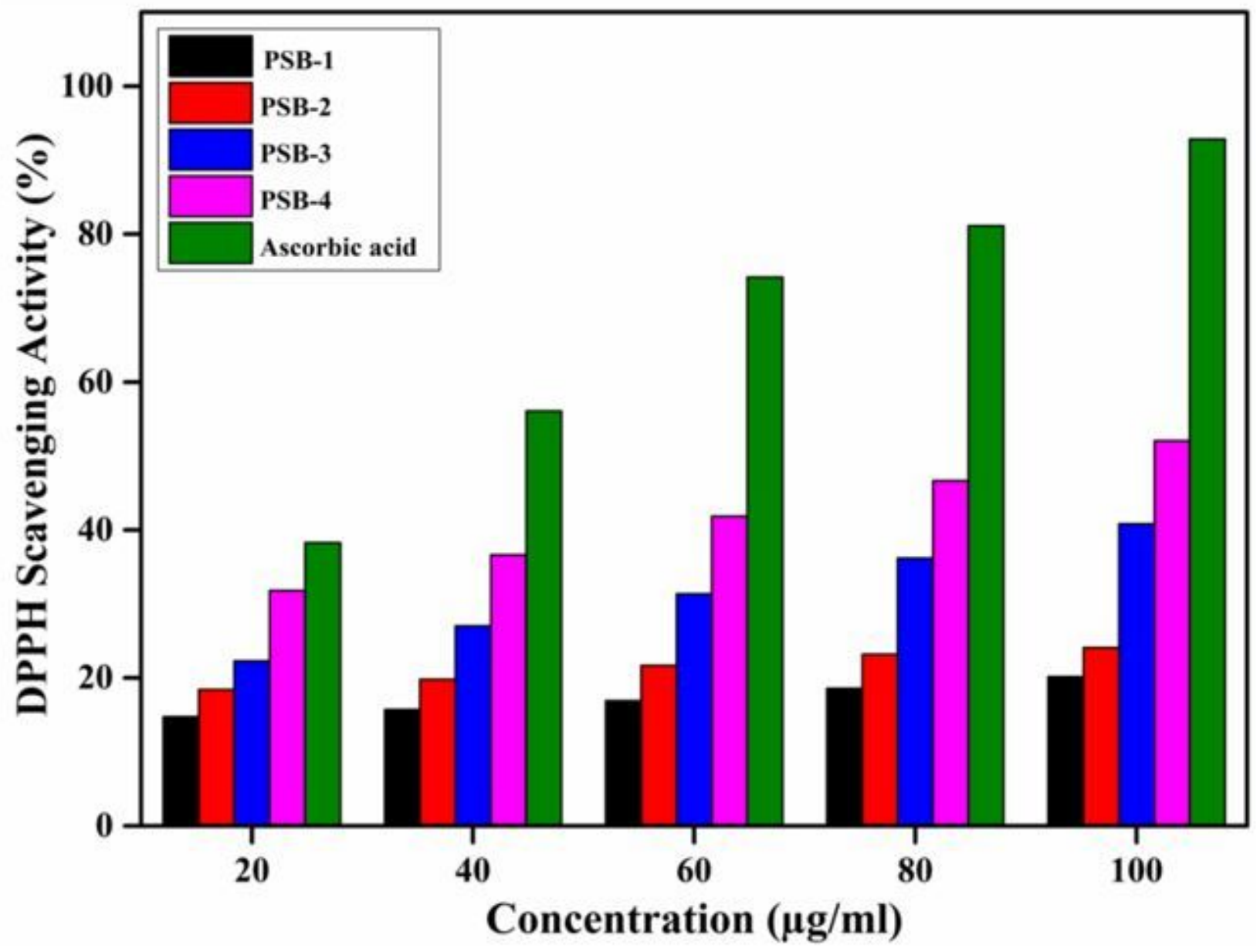

Figure 13

The DPPH scavenging activity PSB blend.

\section{Supplementary Files}

This is a list of supplementary files associated with this preprint. Click to download.

- GraphicalAbstract.tif 